\title{
A Distributed Network for Social Cognition Enriched for Oxytocin Receptors
}

\author{
Mariela Mitre, ${ }^{1,2,3,4}$ Bianca J. Marlin, ${ }^{1,2,3,4}$ Jennifer K. Schiavo, ${ }^{1,2,3,4}$ Egzona Morina, ${ }^{1,2,3,4}$ Samantha E. Norden, ${ }^{1,5,6}$ \\ Troy A. Hackett, ${ }^{7}$ Chiye J. Aoki, ${ }^{8}$ Moses V. Chao, ${ }^{1,2,4,5,6,8}$ and Robert C. Froemke ${ }^{1,2,3,4,8}$ \\ ${ }^{1}$ Skirball Institute for Biomolecular Medicine, ${ }^{2}$ Neuroscience Institute, ${ }^{3}$ Department of Otolaryngology, ${ }^{4}$ Department of Neuroscience and Physiology, \\ ${ }^{5}$ Department of Cell Biology, and ${ }^{6}$ Department of Psychiatry, New York University School of Medicine, New York, New York 10016, ${ }^{7}$ Vanderbilt Kennedy \\ Center for Research on Human Development, Department of Hearing and Speech Sciences, Vanderbilt University School of Medicine, Nashville, Tennessee \\ 37232, and ${ }^{8}$ Center for Neural Science, New York University, New York, New York 10003
}

Oxytocin is a neuropeptide important for social behaviors such as maternal care and parent-infant bonding. It is believed that oxytocin receptor signaling in the brain is critical for these behaviors, but it is unknown precisely when and where oxytocin receptors are expressed or which neural circuits are directly sensitive to oxytocin. To overcome this challenge, we generated specific antibodies to the mouse oxytocin receptor and examined receptor expression throughout the brain. We identified a distributed network of female mouse brain regions for maternal behaviors that are especially enriched for oxytocin receptors, including the piriform cortex, the left auditory cortex, and CA2 of the hippocampus. Electron microscopic analysis of the cerebral cortex revealed that oxytocin receptors were mainly expressed at synapses, as well as on axons and glial processes. Functionally, oxytocin transiently reduced synaptic inhibition in multiple brain regions and enabled long-term synaptic plasticity in the auditory cortex. Thus modulation of inhibition may be a general mechanism by which oxytocin can act throughout the brain to regulate parental behaviors and social cognition.

Key words: antibody; auditory cortex; development; inhibition; oxytocin; synaptic plasticity

\section{Significance Statement}

Oxytocin is an important peptide hormone involved in maternal behavior and social cognition, but it has been unclear what elements of neural circuits express oxytocin receptors due to the paucity of suitable antibodies. Here, we developed new antibodies to the mouse oxytocin receptor. Oxytocin receptors were found in discrete brain regions and at cortical synapses for modulating excitatory-inhibitory balance and plasticity. These antibodies should be useful for future studies of oxytocin and social behavior.

\section{Introduction}

Oxytocin is an evolutionarily conserved peptide that binds to a G-protein-coupled receptor with a single isoform (Richard et al.,

Received June 24, 2015; revised Jan. 18, 2016; accepted Jan. 20, 2016

Author contributions: M.M., M.V.C., and R.C.F. designed research; M.M., B.J.M., J.K.S., E.M., S.N., T.A.H., and C.J.A. performed research; M.M., M.V.C., and R.C.F. contributed unpublished reagents/analytic tools; M.M., B.J.M., J.K.S., E.M., T.A.H., C.J.A., and R.C.F. analyzed data; M.M., M.V.C., and R.C.F. wrote the paper.

This work was funded by the National Institute on Deafness and Other Communication Disorders (NIDCD)National Institutes of Health (Grant DC009635), a McKnight Scholarship, a Pew Scholarship, a Klingenstein Scholarship, a Sloan Research Fellowship, and a Whitehead Foundation Fellowship (R.C.F.); a Skirball Institute Collaborative Research Award (M.V.C. and R.C.F.); National Eye Institute-National Institutes of Health (Core Grants EY13079 and R21MH105846 to (.A.); the National Institute of Neurological Disorders and Stroke-National Institutes of Health (Grant NS21072 to M.V.C.); and the National Institute of Mental Health-National Institutes of Health (Grant T32 to B.J.M.). RNAseq was supported by the NIDCD (Grant DC012527 to T.A.H. and Grant DC009836 to D.B.P.) and the Vanderbilt Kennedy Center (Infrastructure Grant P30-HD015052-33).We thank J.C. Arevalo, I. Carcea, V. Fu, M. Jin, B.Y.B. Lau, D. Lin, N. Lopez, W. Piper, D.B. Polley, D. Rebibo, L. Rubin, S. Sanchez, R.W. Tsien, L.J. Young, and N. Zaika for comments, discussions, and technical assistance and C.A. Loomis and the NYU School of Medicine Histology Core for assistance with anatomical studies. Oxytocin-IRES-Cre mice were obtained from D. Olson (University of Michigan) and B. Lowell (Harvard University). Oxytocin receptor knock-out mice were obtained from K. Nishimori (Tohoku
1991; Kimura et al., 1992; Kubota et al., 1996; Gimpl and Fahrenholz, 2001; Knobloch et al., 2012). Oxytocin is synthesized and released from the supraoptic nucleus (SON) and the paraventricular nucleus (PVN) of the hypothalamus to produce a number of physiological effects involved in mammalian social behavior (Dulac et al., 2014; Rilling and Young, 2014). Lactation and parturition are controlled by peripheral release of oxytocin and oxytocin signaling within the CNS is important for behaviors such as mating, pair bond formation, and child rearing (Pedersen and Prange, 1979; McCarthy, 1990; Nishimori et al., 1996; Insel and Young, 2001; Takayanagi et al., 2005; Bartz et al., 2011;

University) and R.W. Tsien (NYUSchool of Medicine). Oxytocin receptor plasmid (pAAV-OXTR) was obtained from L.J. Young (Emory University). AAV was obtained from the University of Pennsylvania Vector Core.

The authors declare no competing financial interests.

Correspondence should be addressed to either Moses V. Chao or Robert C. Froemke, Skirball Institute, NYU School of Medicine, 540 First Avenue, New York, NY 10016, E-mail: moses.chao@med.nyu.edu or robert.froemke@med.nyu.edu.

DOI:10.1523/JNEUROSCI.2409-15.2016

Copyright $@ 2016$ the authors $\quad 0270-6474 / 16 / 362517-19 \$ 15.00 / 0$ 
Wacker and Ludwig, 2012). It is believed that the forebrain distribution of oxytocin receptors is critical for social behaviors (Insel and Shapiro, 1992; Olazábal and Young, 2006), but the precise expression pattern of oxytocin receptors and downstream consequences of oxytocin receptor signaling remain unclear.

A significant barrier to physiological studies of oxytocin is the lack of adequate oxytocin receptor antibodies suitable for immunohistochemistry and electron microscopy. Previously, receptor distribution was examined by RNA in situ hybridization or autoradiography using radioligands, revealing the general anatomical areas believed to express oxytocin receptors (Elands et al., 1988; Tribollet et al., 1989; Gutkowska et al., 1997; Insel and Young, 2001). However, autoradiography lacks cellular resolution and synapse-type or cell-type specificities required for in-depth study of neural circuits sensitive to oxytocin. More recently, transgenic methods combined with viral expression systems have been used to tag oxytocin receptors with fluorescent reporters such as GFP (Nakajima et al., 2014) or the Venus variant of YFP (Yoshida et al., 2009). These important studies have highlighted several regions and cell types regulated by oxytocin, including somatostatin-positive interneurons of prefrontal cortex involved in sexual behavior (Nakajima et al., 2014) and serotonergic neurons of the raphe nuclei that control anxiety (Yoshida et al., 2009) and project to nucleus accumbens for social reward (Dölen et al., 2013). One caveat of these approaches is that transgene expression could interfere with the endogenous expression profile (Harris et al., 2014), especially given the large number of regulatory elements controlling transcription and tissue-specific localization of the oxytocin receptor (Gimpl and Fahrenholz, 2001).

Therefore, we aimed to develop specific antibodies for the mouse oxytocin receptor. Commercially available antibodies to the oxytocin receptor are not sufficiently sensitive nor specific enough to detect cell-type expression (Yoshida et al., 2009). An additional issue is the sequence similarity between the oxytocin receptor and receptors for vasopressin, another peptide hormone important for social behaviors (Dulac et al., 2014; Rilling and Young, 2014). Therefore, we chose specific sequences in the oxytocin receptor that differed significantly from vasopressin receptors. After purifying and validating these antibodies, we investigated where oxytocin receptors were found in the mouse brain by examining receptor localization across different areas and also in subcellular compartments (including excitatory and inhibitory synapses) using electron microscopy.

Recently, we showed how oxytocin affects cortical circuits to enable maternal behavior (Marlin et al., 2015). In particular, oxytocin enables mice to recognize the behavioral significance of infant distress vocalizations. Expression of maternal retrieval behavior is enhanced by oxytocin (Ehret, 1987; Koch and Ehret, 1989 ) and seems to require plasticity specifically within left auditory cortex to reorganize excitatory and inhibitory inputs for successful processing of pup distress calls (Marlin et al., 2015). Therefore, we focused our analysis on receptor expression within auditory cortex to determine the anatomical and physiological basis of this functional specialization and to describe the elements of cortical circuits sensitive to oxytocinergic modulation. We also investigated whether there were general principles of oxytocin receptor expression and function depending on sex, experience, age, and subcellular location. Our results indicate that oxytocin modulation is important for regulating excitatory-inhibitory balance and plasticity in the auditory cortex and possibly throughout the brain.

\section{Materials and Methods}

Production of oxytocin receptor antibodies. All procedures were approved under New York University Institutional Animal Care and Use Committee protocols. Four custom peptides were synthesized based on the mouse oxytocin receptor amino acid sequence: ELDLGSGVPPGAEGNLTAGPPRRNE (aa 12-36; OXTR-1) at the N terminus, EGSDAAGGAGRAALARVSSVKLISKAKI (aa 243-270; OXTR-2) in the third intracellular loop, and CCSARYLKGSRPGETSISKK (aa 345-365; OXTR-3) and KKSNSSTFVLSRCSSSQRSCSQPSSA (aa 363-388; OXTR-4) at the C terminus. These target peptides were chosen based on a high level of antigenicity using the Thermo Scientific Antigen Profiler. BLAST analysis was performed to ensure the uniqueness of these sites in the mouse proteome. The peptides were generated by AnaSpec with a terminal cysteine added to each peptide to allow for conjugation to keyhole limpet hemocyanin (KLH). KLH conjugation and injection into rabbits was performed by the Pocono Rabbit Farm \& Laboratory. Each rabbit was injected with the respective peptide solution biweekly and a small bleed was collected monthly. The resulting polyclonal antisera were tested using dot and Western blot and immunohistochemistry before being further purified using affinity chromatography.

The immune serum of each rabbit contains many antibodies; therefore, recovery of the oxytocin receptor antibodies was accomplished via affinity purification. A peptide column was built for each of the four different peptides. Then, $2.5 \mathrm{mg}$ of peptide in $2 \mathrm{ml}$ of PBS, $\mathrm{pH}$ 8.0, and 10 $\mathrm{mg}$ of high-quality bovine serum albumin (BSA; Sigma-Aldrich) were mixed in a glass tube. A crosslinking agent, 3-maleimidobenzoic acid $\mathrm{N}$-hydroxysuccinimide ester (1.5 mg; Sigma-Aldrich) was dissolved in 50 $\mu \mathrm{l}$ of DMSO, added to the peptide-BSA solution, and stirred for $1 \mathrm{~h}$ to allow for coupling. The optical density (OD) of the solution was examined at $280 \mathrm{~nm}$. CNBr-activated Sepharose 4B beads (GE Healthcare) were then suspended in $1 \mathrm{~mm} \mathrm{HCl}$ and then washed with PBS to neutralize the $\mathrm{pH}$. The resin was mixed with the peptide/BSA solution and incubated overnight at $4^{\circ} \mathrm{C}$. The OD of this peptide-BSA mixture was again examined at $280 \mathrm{~nm}$ to ensure $>80 \%$ binding of the complex to the column beads. The column was washed with PBS and $0.1 \mathrm{~m}$ Tris, $\mathrm{pH}$ 8.0, before being washed extensively with sodium acetate $(0.1 \mathrm{M})$ and $\mathrm{NaCl}$ in TBS. The column was equilibrated with a $0.1 \%$ Tween 20 solution in Tris-buffered saline (TBST), spun and filtered, and then incubated overnight with column resin at $4^{\circ} \mathrm{C}$. Sera flow-through was collected and washed with $200-300 \mathrm{ml}$ of TBST. Glycine- $\mathrm{HCl}(4-5 \mathrm{ml})$ was added to the column for $10 \mathrm{~min}$. Antibodies were then eluted into tubes with $40 \mu \mathrm{l}$ of $1 \mathrm{~m}$ Tris, $\mathrm{pH} 9.0$, and $40 \mu \mathrm{l}$ of $5 \mathrm{M} \mathrm{NaCl}$ for each milliliter of elute. Protein concentration was measured via OD at $280 \mathrm{~nm}$ and a sample of each fraction run on an SDS-PAGE gel stained with Coomassie Brilliant Blue to assess presence of antibodies as a protein band for light $(\sim 25$ $\mathrm{kDa})$ and heavy chains $(\sim 50 \mathrm{kDa})$ of IgG. Further specificity testing was done for each fraction via immunohistochemistry in wild-type and oxytocin receptor knock-out brain sections.

Specificity of antibodies was further evaluated via Western blot analysis of HEK293 cells expressing an oxytocin receptor-Venus construct (provided by L.J. Young, Emory University) and protein extracts from mouse uterus and brain. Untransfected HEK293 cells, as well as tissues from the oxytocin-receptor knock-out uterus and brain, were used as controls in each Western blot analysis. The isolation of protein was done using a lysis buffer consisting of $50 \mathrm{~mm}$ Tris, $\mathrm{pH} 8.0,1 \%$ Nonidet $\mathrm{P}-40,10$ mm ethylenediaminetetraacetic acid, 0.1\% Triton X-100, 0.1\% SDS, 150 $\mathrm{mm} \mathrm{NaCl}$, and freshly added phosphatase and protease inhibitors (Roche). Lysates were spun for $10 \mathrm{~min}(15,000 \mathrm{rpm})$ to pellet the nuclear fraction and the protein content of the supernatant was assayed using spectrophotometry. Next, $20 \mu \mathrm{g}$ of protein from cell lysates and $50-75$ $\mu \mathrm{g}$ of protein from tissue lysates were separated by SDS-PAGE and transferred to PVDF membranes. Nonspecific antibody binding was blocked by incubating blots with 5\% milk in TBST buffer (20 mM Tris, $137 \mathrm{~mm}$ $\mathrm{NaCl}, 0.1 \%$ Tween 20 ) or $3 \%$ BSA in TBST. Membranes were washed in TBST buffer and incubated in oxytocin receptor antibody $(1 \mu \mathrm{g} / \mathrm{ml})$ overnight at $4^{\circ} \mathrm{C}$. The next morning, membranes were washed in TBST and then incubated for $1 \mathrm{~h}$ at room temperature with horseradish peroxidase-conjugated anti-rabbit secondary antibodies. The mem- 
branes were washed with TBST and then the signal was visualized with enhanced chemiluminescence (GE Healthcare). Controls were done by using preimmune sera and target peptide immunoblots to show specificity of bands for the oxytocin receptor.

For immunohistochemical analysis with light microscopy, wild-type or oxytocin receptor knock-out C57BL/6 mice were anesthetized via intraperitoneal injection $(0.1 \mathrm{ml}$ per $10 \mathrm{~g})$ of a ketamine-xylazine mixture containing $15 \mathrm{mg} / \mathrm{ml}$ ketamine and $5 \mathrm{mg} / \mathrm{ml}$ xylazine in $0.9 \%$ sodium chloride solution. Mice were perfused intracardially with a solution of heparin (1000 units/ml) and PBS to prevent clotting, followed by $40 \mathrm{ml}$ per mouse of freshly prepared $4 \%$ paraformaldehyde in $10 \mathrm{~mm}$ phosphate buffer. The brains were carefully removed and postfixed in $4 \%$ paraformaldehyde for $2 \mathrm{~h}$ at $4^{\circ} \mathrm{C}$ and then cryoprotected overnight in $30 \%$ sucrose at $4^{\circ} \mathrm{C}$. The brains were then embedded in a cryoprotectant medium (Tissue Tek Optimal Cutting Temperature Medium; VWR) and stored at $-80^{\circ} \mathrm{C}$ until they were sectioned. Coronal $16 \mu \mathrm{m}$ sections were cut on a cryostat and collected on SuperFrost Plus glass slides (Fisher Scientific). Sections were washed in PBS and blocked for $2-3 \mathrm{~h}$ at room temperature in PBS containing $0.2 \% \mathrm{v} / \mathrm{v}$ Triton X-100 and 5\% v/v normal donkey serum. The blocking solution was aspirated and the sections were incubated with oxytocin receptor primary antibody diluted in block to a concentration of $1 \mu \mathrm{g} / \mathrm{ml}$. Sections were incubated for $2 \mathrm{~d}$ at $4^{\circ} \mathrm{C}$ in a moist chamber. Sections were washed with PBS $(3 \times 15 \mathrm{~min}$ at room temperature) in a staining jar and incubated for $1-2 \mathrm{~h}$ at room temperature in Alexa Fluor-conjugated secondary antibodies diluted 1:500 in PBS. Any unbound secondary antibody was washed with PBS $(3 \times 15$ $\mathrm{min}$ at room temperature) and sections were incubated for $15 \mathrm{~min}$ at room temperature with a DAPI solution (1:10,000 stock diluted in PBS) for nuclear staining. After a final rinse, the slides were coverslipped using fluoromount G (Southern Biotechnology Associates). The brains of wild-type and knock-out animals were processed together to minimize any confounding factors and parallel sections from knock-out animals served as controls. As a control, omission of primary antibody eliminated immunofluorescent labeling from that channel.

Quantification of OXTR-2+ cells. Slides were examined and imaged using a Carl Zeiss LSM 700 confocal microscope with four solid-state lasers $(405 / 444,488,555,639 \mathrm{~nm})$ and appropriate filter sets. For imaging sections costained with multiple antibodies, short-pass $555 \mathrm{~nm}$ (Alexa Fluor 488), short-pass $640 \mathrm{~nm}$ (Alexa Fluor 555), and long-pass 640 $\mathrm{nm}$ (Alexa Fluor 647) photomultiplier tubes were used. The distribution and number of immunoreactive cells in each section were determined by taking images of wild-type and knock-out sections under the same laser power output, pinhole aperture, and gain. Images from each brain area were collected and saved for manual counts by two independent blinded observers. Maximum intensity projections of image stacks are shown, each representing at least six to eight distinct optical planes. Brain areas in these sections were identified according to stereotaxic coordinates (Franklin and Paxinos, 2007). In six animals, estrous state was first determined by daily collection of vaginal secretions (Caligioni, 2009) smeared onto a Superfrost Plus microscope slide. Estrous state was identified under a light microscope at $10 \times$ using the criteria of Byers et al. (2012). Animals were then anesthetized, perfused, sectioned, and stained. Quantification of OXTR-2+ cells in these animals was performed blind to estrous state.

Quantification of oxytocin receptor mRNA using real-time PCR. Acute coronal slices of auditory cortex ( $350 \mu \mathrm{m}$ thick) were prepared from postnatal day 40 (P40)-P70 C57BL/6 virgin female mice with a vibratome (Leica). Animals were deeply anesthetized with isoflurane and decapitated. The brain was rapidly submerged in ice-cold dissection buffer containing the following (in $\mathrm{mM}$ ): $87 \mathrm{NaCl}, 75$ sucrose, $2 \mathrm{KCl}, 1.25$ $\mathrm{CaCl}, 7 \mathrm{MgCl} 2,25 \mathrm{NaHCO}_{3}, 1.3$ ascorbic acid, and 10 dextrose. A dissecting microscope was used to determine the location of auditory cortex in each slice and a 1-mm-diameter microcurette was used to obtain homologous punches of left and right auditory cortex, which were then flash frozen in dry ice.

Total RNA was isolated using TRIzol reagent (Invitrogen) and quantified using a NanoDrop spectrophotometer (Thermo Scientific). Equal amounts of RNA for left and right samples were purified using a DNase I digestion kit (Invitrogen) and reverse transcribed into cDNA using the
SuperScript III First-Strand Synthesis System (Invitrogen) in a Veriti 96 well thermal cycler (Applied Biosystems). Quantitative PCR was performed using a mouse oxytocin receptor Taqman probe (Life Technologies, assay ID: Mm01182684_ml) and amplification was performed using a Step One Plus Real-Time PCR System (Life Technologies). Controls lacking random hexamers, reverse transcriptase, or oxytocin receptor Taqman probe were run to verify the lack of contamination in the preparation. qPCR assays were performed in triplicate per sample on 96-well plates. Left and right samples from the same animal were run on the same plate and the ddCT method was used to determine the relative oxytocin receptor transcript level with ribophorin assay (Life Technologies, assay ID: Mm00505837_m1) as endogenous controls (Livak and Schmittgen, 2001). Oxytocin receptor mRNA levels of left and right auditory cortex were compared by Student's paired two-tailed $t$ test because the data passed Kolmogorov-Smirnov normality tests.

Quantification of oxytocinergic fiber densities. For viral injections, OxtIRES-Cre animals were bred into a C57BL/6 background. Female mice $2-4$ months old were anesthetized with isoflurane (0.5-2.5\%). A craniotomy was performed over the left PVN using stereotaxic coordinates (from bregma in mm: 0.7 posterior, 0.25 lateral, 4 ventral) and pAAV5Ef1a-DIO-ChETA-EYFP $(1-1.2 \mu \mathrm{l})$ was injected $(0.1 \mu \mathrm{l} / \mathrm{min})$. Animals were given at least 2 weeks to recover and allowed for adequate expression of YFP and the ChETA variant of channelrhodopsin-2.

Perfusion and immunohistochemical processing of these animals was conducted as described above. YFP-positive cells and their projections were detected via a chicken anti-GFP primary antibody (1: 1000; Abcam) and a goat anti-chicken Alexa Fluor 488 secondary antibody. Confocal images were acquired with a Carl Zeiss LSM 700 confocal microscope and consisted of a $z$-stack that spanned the thickness of the section. Maximum intensity projections of image stacks are shown, each representing at least six to eight distinct optical planes. YFP + cells and fibers were costained with an oxytocin peptide antibody (MAB5296; Millipore).

For axon length measurements, YFP-positive axon segments in OxtIRES-Cre animals were quantified with the NeuronJ plugin in ImageJ by one blinded observer. Traces of the fibers and puncta were drawn over each image of areas of interest analyzed for OXTR-2 expression, as well as additional brain regions that revealed YFP-positive fibers. Fiber length was normalized to area of the acquired image, which covered a specific anatomic brain region.

Electron microscopy. Brains were collected from oxytocin receptor knock-out and wild-type littermate mice at 6-10 weeks of age (provided by Richard W. Tsien and Katsuhiko Nishimori). Wild-type and knockout animals were processed in parallel to ensure equalized labeling conditions. Mice were deeply anesthetized with urethane (34\%, i.p., $0.1 \mathrm{cc}$ per $15 \mathrm{~g}$ body weight) and transcardially perfused with $20 \mathrm{ml}$ of saline containing heparin $(4000 \mathrm{U} / \mathrm{L})$ delivered using a peristaltic pump set at a flow rate of $25 \mathrm{ml} / \mathrm{min}$. Saline was followed without interruption with $250 \mathrm{ml}$ of $4 \%$ formaldehyde in $0.1 \mathrm{M}$ phosphate buffer (PB) at a flow rate of $25 \mathrm{ml} / \mathrm{min}$. The brains were promptly extracted and postfixed overnight in $4 \%$ formaldehyde. Glutaraldehyde was omitted from the fixation at this stage to optimize preservation of antigenicity.

Free-floating coronal brain sections containing auditory cortex were prepared the next day using a vibratome set to a thickness of $50 \mu \mathrm{m}$. These sections were collected and stored in new plastic multiwell plates (Corning) suspended in a solution of $0.01 \mathrm{M} \mathrm{PB}$ with $0.9 \%$ sodium chloride, $\mathrm{pH} 7.4$, and containing $0.05 \%$ sodium azide for preservation (PBSazide). The sections were blocked for 30 min under constant agitation with $1 \%$ bovine serum albumin in PBS-azide (BSA-PBS-Azide) and then incubated for $40 \mathrm{~h}$ at $4^{\circ} \mathrm{C}$ in OXTR-2 diluted in BSA-PBS-Azide at the following dilutions: 1:1000, 1:3500, or 1:5000 with or without preadsorption with $1 \mathrm{mg} / \mathrm{ml}$ control peptide. Sections were rinsed 3 times for 10 min in PBS-Azide to remove unbound antibodies and then incubated for $1 \mathrm{~h}$ at room temperature with horse anti-rabbit biotinylated antibody diluted 1:200 in BSA-PBS-Azide. Sections were rinsed to remove unbound secondary antibody and then incubated for $30 \mathrm{~min}$ in the $\mathrm{A}+\mathrm{B}$ solution of the ABC Elite kit (Vector Laboratories). In parallel, 3,3'diaminobenzidine $\mathrm{HCl}$ (DAB; Sigma-Aldrich) solution was prepared by dissolving $10 \mathrm{mg}$ tablets in $44 \mathrm{ml}$ of PBS. Once the sections were rinsed of 
$\mathrm{A}+\mathrm{B}$ solution, $\mathrm{DAB}$ solution was activated by adding $4 \mu \mathrm{l}$ of $30 \%$ hydrogen peroxide per 44 $\mathrm{ml}$ of DAB solution. The activated product was promptly added to the sections and the reaction was stopped after $8 \mathrm{~min}$ by transferring the sections to PBS and rinsing them repeatedly. The sections were postfixed for $15 \mathrm{~min}$ in a $2 \%$ glutaraldehyde in PBS solution, rinsed, and then stored in PBS-Azide at $4^{\circ} \mathrm{C}$.

Next, sections were processed for electron microscopy by postfixing with $1 \%$ osmium tetraoxide in $0.1 \mathrm{M} \mathrm{PB}$ for $1 \mathrm{~h}$, dehydrating with increasing concentrations of ethanol (up to $70 \%$ in water), and then incubating overnight in $1 \%$ uranyl acetate diluted in $70 \%$ ethanol for further preservation of the ultrastructure and contrast enhancement of membranes. On the next day, sections were further dehydrated by increasing concentrations of ethanol up to $100 \%$, rinsed in $100 \%$ acetone, and then infiltrated with EPON 812 (EM Science). The sections were carefully placed between two Aclar plastic sheets held flat by a lead weight on top of the Aclar and cured at $60^{\circ} \mathrm{C}$ for $24-36 \mathrm{~h}$. The flat-embedded sections were then reembedded in EPON 812-filled Beem capsules and cured. The position of the auditory cortex in each tissue was visualized by light microscopy and identified using landmarks such as the external capsule and the hippocampal anatomy. The embedded tissue was ultrathin sectioned at an orientation tangential to the vibratome sections because that surface was maximally exposed to the antibody. The ultrathin sections were placed 400-mesh Formvar-coated nickel grids.

Images were captured using a 1.2 megapixel Hamamatsu CCD camera from AMT from the JEOL 1200XL Electron Microscope. Experimenters were kept blind to the animal genotypes while capturing images and quantifying the frequency of immunolabeled profiles. Care was taken to capture images very close to the EPON-tissue interface in all animals because these areas had maximal contact with antibody and therefore immunoreactivity would be highest. Electron microscopic examination was performed on a total of four wild-type and four oxytocin receptor knock-out mice. Two to four sections per animal were examined. Nonoverlapping micrographs $(3.4 \times 3.4 \mu \mathrm{m}$ in area captured at a magnification of $40,000 \times$ ) were collected (36-191 micrographs for wildtype, 49-168 micrographs for oxytocin receptor knock-outs). Within each section, micrographs were serially collected in a systematic, contiguous manner such that, after collecting one micrograph, the adjoining area was then imaged without any overlap. This procedure ensured that micrographs were captured randomly, except for the constraint of imaging as close as possible to the EPON-tissue interface, regardless of whether an immunolabeled profile was present in the field. Profiles in each micrograph were categorized by type (excitatory synapse, inhibitory synapse, axon, dendritic shaft, dendritic spine, cell body, glia) and then examined for localization of immunoreactivity (presynaptic, postsynaptic, intracellular, plasma membrane). Asymmetric synapses were identified by thick postsynaptic densities (PSDs) on a portion of membrane adjacent to a vesicle-filled axon terminal and were presumably excitatory. Synapses were categorized as symmetric and inhibitory if they lacked the thick PSDs (Peters et al., 1991). Axons of passage were recognized by the presence of synaptic vesicles and lack of synaptic junction within that micrograph. Dendritic shafts had microtubule arrays and glial cells were identified by their irregular boundaries and absence of microtubules (Peters et al., 1991). Binomial statistics were used to calculate means and $95 \%$ confidence intervals as synapses and cytoplasm were scored as being either labeled or unlabeled. Fisher's exact $t$ tests were used
OXTR-1 $\begin{array}{ll}\text { MEGTPAANWS IELDLGSGV--PPGAEGNLTAGPPRRNEALARVEVAVLCL } & 48 \\ \text { PAGNSSPWWPLTTEGANSSREAAGLGEGGSPPGDVRNEELAKLEVTVLAV } 60\end{array}$ MDS--EPSWTATPSPGGTL--E---VPNTTTPWLGRDEELAKVEIGILAT 43

$$
* . . * * * * * * * * * * \star * * \text {. }
$$

OXYR MOUSE ILFLALSGNACVLLALRTTRHKHSRLFFFMKHLS IADLVVAVFQVLPQLLWDITFRFYGP 108

OXYR_MOUSE DLLCRLVKYLQVVGMFASTYLLLLMSLDRCLAICQPLRSLRRRTDR--LAVLATWLGCLV 166 V1AR MOUSE DWLCRVVKHLOVFAMFASSYMLVVMTADRYIAVCHPLKTLOOPARRSRLMIAASWGLSFV 180

OXYR_MOUSE ASVPQVHIFSLREV--A--DGVFDCWAVFIQPWGPKAYVTWITLAVYIVPVIVLAACYGL 222 V1AR_MOUSE LSIPQYFIFSVIEFEVNNGTKAQDCWATFIPPWGTRAYVTWMTSGVFVVPVIILGTCYGF 240

OXYR MOUSE ISFKIWONLRLKTAAAAAAAEGS-----DAAGGAGRA--ALARVSSVKLISKAKIRTVKM 275 OXTR-2

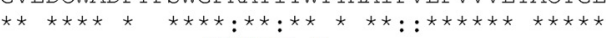

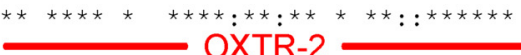
V1AR_MOUSE ICYHIWRNVRGKTASRQSKG-G--KGSGEAAGPFHKGLLVTPCVSSVKSISRAKIRTVKM 297

OXYR_MOUSE TFIIVLAFIVCWTPFFFVQMWSVWDVNAPKEAS---AFIIAMLLASLNSCCNPWIYMLET 332 VIAR MOUSE TFVIVSAYILCWTPFFIVQMWSVWDTNFVWTDSENPSTTITALLASLNSCCNPWIYMFES 357

OXYR_MOUSE GHLFHELVQRFLCCSARYLKGSRPGE TSISKKSNSSTFVLSRRSSSQRSCSQPSSA---- 388 V1AR MOUSE GHLLQDCVQSFPCCOSIAQKFAKDDSDSMSRRQTSYSNNRSPTNST----G-------- 404 OXYR MOUSE -------------------------

VIAR MOUSE -TWKDSPKSSKSIRFIPVST---------- 423

Figure 1. Design of oxytocin receptor antibodies. Aligned sequences of mouse oxytocin receptor and vasopressin V1a/V1b receptors. The four epitope sequences (OXTR-1,2,3,4) chosen for antibody generation are highlighted in bold. *Amino acid identity between oxytocin receptor and either V1a and/or V1b receptor; ":" or ".", amino acid similarity between oxytocin receptor and either V1a and/or V1b receptor (":" represents similarity of $>0.5$ in the Gonnet-PAM 250 matrix).

to determine significant differences in immunolabeling between wildtype and oxytocin receptor knock-out tissues. Cytoplasmic labeling within axons, dendritic shafts, dendritic spines, and glia were normalized to the total number of synapses examined (cytoplasmic labels per 100 synapses) to compare labeling across wild-type and knock-out brain tissues.

Next-generation sequencing of total RNA. Frozen brains from six animals in each age group (three male, three female) were sectioned in the coronal plane (rostral to caudal) on a sliding microtome and viewed through a surgical microscope (Hackett et al., 2015). As areas targeted for sampling became visible, they were extracted using a sterile tissue punch or curette of a size appropriate to the brain region. Samples of auditory cortex were obtained using a $0.5-\mathrm{mm}$-diameter punch with the ventral edge beginning $\sim 1 \mathrm{~mm}$ dorsal to the rhinal fissure. Samples of MGB were harvested with a curette after using a microdissecting scalpel to circumscribe its perimeter; the microdissection procedure was designed to exclude the lateral geniculate nucleus and adjoining nuclei dorsal, medial, and ventral to the MGB. The extreme rostral and caudal poles of the MGB were largely excluded from these samples. Punches from homologous areas of both hemispheres were combined in sterile tube containing $400 \mu \mathrm{l}$ of TRIzol, homogenized for $45 \mathrm{~s}$ using a mechanized sterile pestle, flash frozen on dry ice, then stored at $-80^{\circ} \mathrm{C}$.

For each TRIzol lysate, $100 \mu \mathrm{l}$ of Reagent Grade Chloroform (Fisher Scientific, S25248) was added. The samples were centrifuged for $3 \mathrm{~min}$ on a desktop centrifuge to fractionate the aqueous and organic layers. After centrifugation, the resulting aqueous layer was carefully removed and transferred to $2.0 \mathrm{ml}$ tubes (Sarstedt, 72.694) run on QIAsymphony using the QIAsymphony RNA Kit (Qiagen, 931636) and protocol RNA_CT_400_V7, which incorporates DNase treatment. Before each run, the desk was UV irradiated using the 
A

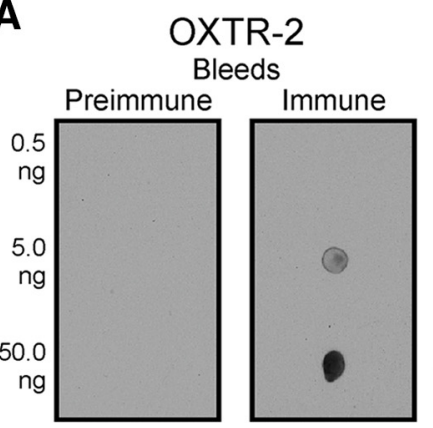

B

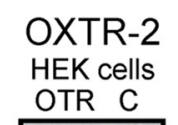

C

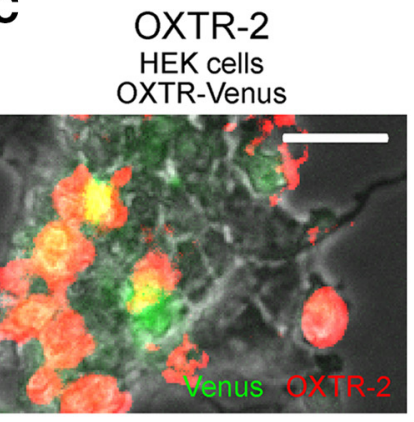

D
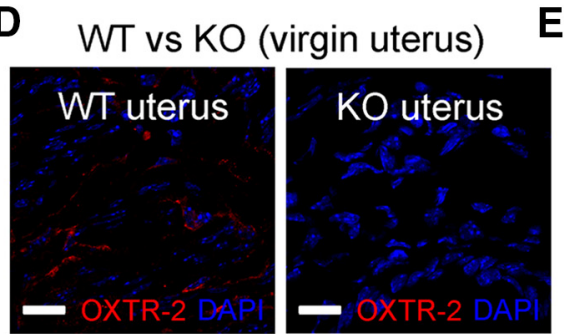

E

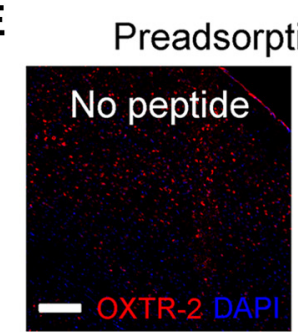

counts for OXTR were obtained by dividing raw read counts against total read count in the sample and multiplying by $10^{6}$. Normalized read counts were averaged over all samples for each age (P7, P14, P21, adult) and brain region (auditory cortex, auditory thalamus). ANOVA with Tukey post hoc testing was used to screen for significant differences in expression between ages for each brain area and gene.

In vitro electrophysiology. Acute slices of left auditory cortex, piriform cortex, and PVN were prepared from adult virgin female C57BL/6 mice. Animals were deeply anesthetized with a 1:1 ketamine/xylazine mixture and decapitated. The brain was rapidly placed in ice-cold dissection buffer containing the following (in $\mathrm{mm}$ ): $87 \mathrm{NaCl}, 75$ sucrose, $2 \mathrm{KCl}$, $1.25 \mathrm{NaH}_{2} \mathrm{PO}_{4}, 0.5 \mathrm{CaCl}_{2}, 7 \mathrm{MgCl}_{2}, 25$ $\mathrm{NaHCO}_{3}, 1.3$ ascorbic acid, and 10 dextrose, bubbled with $95 \% / 5 \% \mathrm{O}_{2} / \mathrm{CO}_{2}$, $\mathrm{pH}$ 7.4. Slices (300-400 $\mu \mathrm{m}$ thick) were prepared with a vibratome (Leica), placed in warm dissection buffer $\left(33-35^{\circ} \mathrm{C}\right)$ for $<30 \mathrm{~min}$, and then transferred to a holding chamber containing artificial CSF (ACSF) at room temperature containing the following (in mM): $124 \mathrm{NaCl}$, $2.5 \mathrm{KCl}, 1.5 \mathrm{MgSO}_{4}, 1.25 \mathrm{NaH}_{2} \mathrm{PO}_{4}, 2.5 \mathrm{CaCl}_{2}$, and $26 \mathrm{NaHCO}_{3}$. Slices were kept at room temperature $\left(22-24^{\circ} \mathrm{C}\right)$ for $>30$ min before use. For experiments, slices were transferred to the recording chamber and perfused $(2-2.5 \mathrm{ml}$ $\min ^{-1}$ ) with oxygenated ACSF at $33^{\circ} \mathrm{C}$.

Somatic whole-cell recordings were made from layer 5 pyramidal cells in the auditory cortex, layer 2-3 pyramidal cells in piriform cortex, and PVN neurons from either wildtype virgin female mice or virgin female OxtIRES-Cre mice expressing ChETA in oxytocin programmed cycle. The resulting RNA was eluted to $100 \mu$ l of RNase TRIzol-free water and stored at $-80^{\circ} \mathrm{C}$ in $2.0 \mathrm{ml}$ Sarstedt tubes until use. Samples were initially quantitated using a Qubit RNA assay. Additional analyses of purity and the quantitation of total RNA were performed using a NanoDrop spectrophotometer (Thermo Scientific) and Agilent RNA 6000 Pico chip (Agilent) according to the manufacturer's protocol using the reagents, chips, and ladder provided in the kit.

RNAseq was performed by the Vanderbilt Technologies for Advanced Genomics core (VANTAGE) as in Hackett et al. (2015). Total RNA was isolated with the Aurum Total RNA Mini Kit (Bio-Rad). All samples were quantified on the QuBit RNA assay. RNA quality was verified using an Agilent Bioanalyzer. RNAseq data were obtained by first using the RiboZero Magnetic Gold Kit (Human/Mouse/Rat; Epicenter) to perform ribosomal reduction on $1 \mu \mathrm{g}$ of total RNA following the manufacturer's protocol. After ribosomal RNA (rRNA) depletion, samples were purified using the Agencourt RNAClean XP Kit (Beckman Coulter) according to the Epicenter protocol specifications. After purification, samples were eluted in $11 \mu \mathrm{l}$ of RNase-free water. Next, $1 \mu \mathrm{l}$ of ribosomal depleted samples was run on the Agilent RNA 6000 Pico Chip to confirm rRNA removal. After confirmation of rRNA removal, $8.5 \mu$ l of rRNA-depleted sample was input into the Illumina TruSeq Stranded RNA Sample Preparation Kit for library preparation. Libraries were multiplexed 6 per lane and sequenced on the HiSeq 2500 to obtain at least 30 million paired end $(2 \times 50 \mathrm{bp})$ reads per sample.

RNAseq data went through multiple stages of quality control as recommended by Guo et al. (2014a). Raw data and alignment quality control were performed using QC3 (Guo et al., 2014b) and gene quantification quality control was conducted using MultiRankSeq (Guo et al., 2014c). Raw data were aligned with TopHat2 (Kim et al., 2013) against the mouse mm10 reference genome and read counts per gene were obtained using HTSeq (Anders et al., 2015). Normalized read neurons. Recordings were performed in voltage-clamp or current-clamp mode with a Multiclamp 700B amplifier (Molecular Devices) using IRDIC video microscopy (Olympus). Patch pipettes (3-8 M $\Omega$ ) were filled with intracellular solution either for voltage-clamp recordings containing the following (in mM): 130 Cs-methanesulfonate, 1 QX-314, 4 TEACl, 0.5 BAPTA, 4 MgATP, 10 phosphocreatine, 10 HEPES, pH 7.2, or current-clamp recordings containing the following (in $\mathrm{mM}$ ): 135 K-gluconate, $5 \mathrm{NaCl}, 10 \mathrm{HEPES}, 5 \mathrm{MgATP}, 10$ phosphocreatine, and 0.3 GTP. For auditory cortical neurons, the mean series resistance $\left(R_{\mathrm{s}}\right)$ was $31.2 \pm 11.1 \mathrm{M} \Omega(\mathrm{SD}, \mathrm{SD})$ and the mean input resistance $\left(R_{\mathrm{i}}\right)$ was $157.3 \pm$ 64.0 $\mathrm{M} \Omega$, determined by monitoring cells with hyperpolarizing pulses (50 pA or $5 \mathrm{mV}$ for $100 \mathrm{~ms}$ ). For piriform neurons, $R_{\mathrm{s}}$ was $32.6 \pm 14.5$ $\mathrm{M} \Omega$ and $R_{\mathrm{i}}$ was $149.3 \pm 67.1 \mathrm{M} \Omega$. For PVN neurons, $R_{\mathrm{s}}$ was $26.0 \pm 12.6$ $\mathrm{M} \Omega$ and $R_{\mathrm{i}}$ was $329.0 \pm 134.3 \mathrm{M} \Omega$. Recordings were excluded from analysis if $R_{\mathrm{s}}$ or $R_{\mathrm{i}}$ changed $>30 \%$ compared with the baseline period. Data were digitized at $10 \mathrm{kHz}$ and analyzed with Clampfit 10 (Molecular Devices). Focal extracellular stimulation $(0.25 \mathrm{~Hz}$ stimulus rate) was applied with either a bipolar theta glass or metal electrode (Grass, stimulation strengths of 5-150 $\mu \mathrm{A}$ for $0.01-1.0 \mathrm{~ms}$ ) located $100-500 \mu \mathrm{m}$ from the recording electrode. To measure excitatory strength, EPSP initial slope (first $2 \mathrm{~ms}$ ) or mean peak EPSC ( $2.5 \mathrm{~ms}$ window) was used for current-clamp or voltage-clamp recordings, respectively; EPSP slope is correlated with peak amplitude but less prone to contamination by polysynaptic activity (Staff and Spruston, 2003; Sweatt, 2009). EPSCs were measured at hyperpolarized potentials ( -70 to $-85 \mathrm{mV}$ ). For inhibitory currents, a larger window (5-15 ms) was used and IPSCs were measured at depolarized potentials $(-10$ to $-40 \mathrm{mV})$. For optogenetic stimulation, blue light pulse trains were presented at $5 \mathrm{~Hz}$ for $3 \mathrm{~min}$ ( $473 \mathrm{~nm}$ wavelength, $15 \mathrm{~mA}$ light intensity, $100 \mathrm{~ms}$ pulse width duration). Spontaneous EPSCs and IPSCs in these recordings were detected with a template EPSC or IPSC, respectively, and excluded unless the amplitude was $>2$ SDs 
above baseline membrane noise level. The average of all spontaneous event amplitudes and rates was computed (TTX was not included in the bath for these measurements). To examine spike generation, some cells were transiently depolarized by $5-20 \mathrm{mV}$ prior to and during synaptic stimulation; a fixed duration and amount of depolarization was used for a given cell during baseline and postoxytocin measurements. Oxytocin, gabazine (SR95531), DNQX, and APV were purchased from SigmaAldrich. OTA was purchased from Bachem. All statistics and error bars are reported as means \pm SEM and statistical significance was assessed with paired two-tailed Student's $t$ tests.

In vivo electrophysiology. For in vivo electrophysiology, female mice were anesthetized with isoflurane $(0.5-2.5 \%)$. A small craniotomy was performed over left auditory cortex with stereotaxic coordinates (from bregma in mm: 2.9 posterior, 4.0 lateral). In vivo recordings were performed in a sound-attenuating chamber. To ensure recordings or implants were targeted to A1, we first recorded multiunit activity with tungsten electrodes. A1 was mapped with pure tones (60 dB SPL, 2-79 $\mathrm{kHz}$ at $0.2-1$ octave steps, $50 \mathrm{~ms}$ duration, $1-3 \mathrm{~ms}$ cosine on/off ramps) delivered in a pseudorandom sequence at $0.5-1 \mathrm{~Hz}$. After locating A1, in vivo whole-cell current-clamp recordings were made from A1 neurons with a Multiclamp 700B amplifier (Molecular Devices). Patch pipettes (4-9 M $\Omega$ ) contained the following (in $\mathrm{mm}$ ): $135 \mathrm{~K}$-gluconate, $5 \mathrm{NaCl}, 10$ HEPES, 5 MgATP, 10 phosphocreatine, and 0.3 GTP, pH 7.3. Whole-cell recordings from A1 neurons were obtained from cells located 420-800 $\mu \mathrm{m}$ below the pial surface. Data were filtered at $5 \mathrm{kHz}$, digitized at 20 $\mathrm{kHz}$, and analyzed with Clampfit 10 (Molecular Devices). For in vivo recordings of auditory cortical neurons, the mean $R_{\mathrm{s}}$ was $34.0 \pm 22.0 \mathrm{M} \Omega$ (SD) and the mean $R_{\mathrm{i}}$ was $128.2 \pm 82.7 \mathrm{M} \Omega$. Recordings were excluded from analysis if $R_{\mathrm{s}}$ or $R_{\mathrm{i}}$ changed $>30 \%$ compared with the baseline period. For pairing tones with oxytocin, baseline responses to pure tones were recorded for 5-20 min. A tone different from the best frequency was then chosen and presented repetitively for $1-5 \mathrm{~min}$ at $0.5-1 \mathrm{~Hz}$ in the presence of oxytocin $(50 \mu \mathrm{M})$ applied topically via a perfusion system directly over the craniotomy at a flow rate of $4 \mathrm{ml} / \mathrm{min}$ for a total of $3 \mathrm{~min}$. Afterward, oxytocin perfusion was ceased and saline was gently applied to the cortical surface with a syringe. This topically applied oxytocin might diffuse to recorded cells $420-800 \mu \mathrm{m}$ below the pial surface or may act at more superficially located synapses. All statistics and error bars are reported as means \pm SEM and statistical significance was assessed with paired two-tailed Student's $t$ tests.

\section{Results}

OXTR-2, a novel and specific antibody to the mouse oxytocin receptor

To study the cellular distribution of the oxytocin G-proteincoupled receptor in the brain, specific antibodies to the mouse oxytocin receptor were required. We examined the sequence of the mouse oxytocin receptor (Fig. 1) and selected four peptide regions as immunogens based on previous data on antigenicity and the physical and topographical properties of particular regions of the protein. Specifically, we identified epitopes that were maximally different from corresponding regions of the vasopressin $\mathrm{V} 1 \mathrm{a} / \mathrm{V} 1 \mathrm{~b}$ receptors. The affinity of the oxytocin receptor for oxytocin is only 10 -fold greater than that for vasopressin (Postina et al., 1996), indicating that the putative ligand-binding domain of the oxytocin receptor is not a good candidate for generating specific antibodies. Correspondingly, the areas of highest homology between oxytocin and vasopressin receptors are located in the extracellular loops and the transmembrane helices, whereas the $\mathrm{N}$ terminus, $\mathrm{C}$ terminus, and the intracellular loops are less conserved (Gimpl and Fahrenholz, 2001). These differences provided a starting point for choice of epitopes that maximized differences between the oxytocin receptor and the vasopressin V1a and V1b receptors. We prepared peptides called OXTR-1, OXTR-2, OXTR-3, and OXTR-4 (Fig. 1) and used each for rabbit immunization.
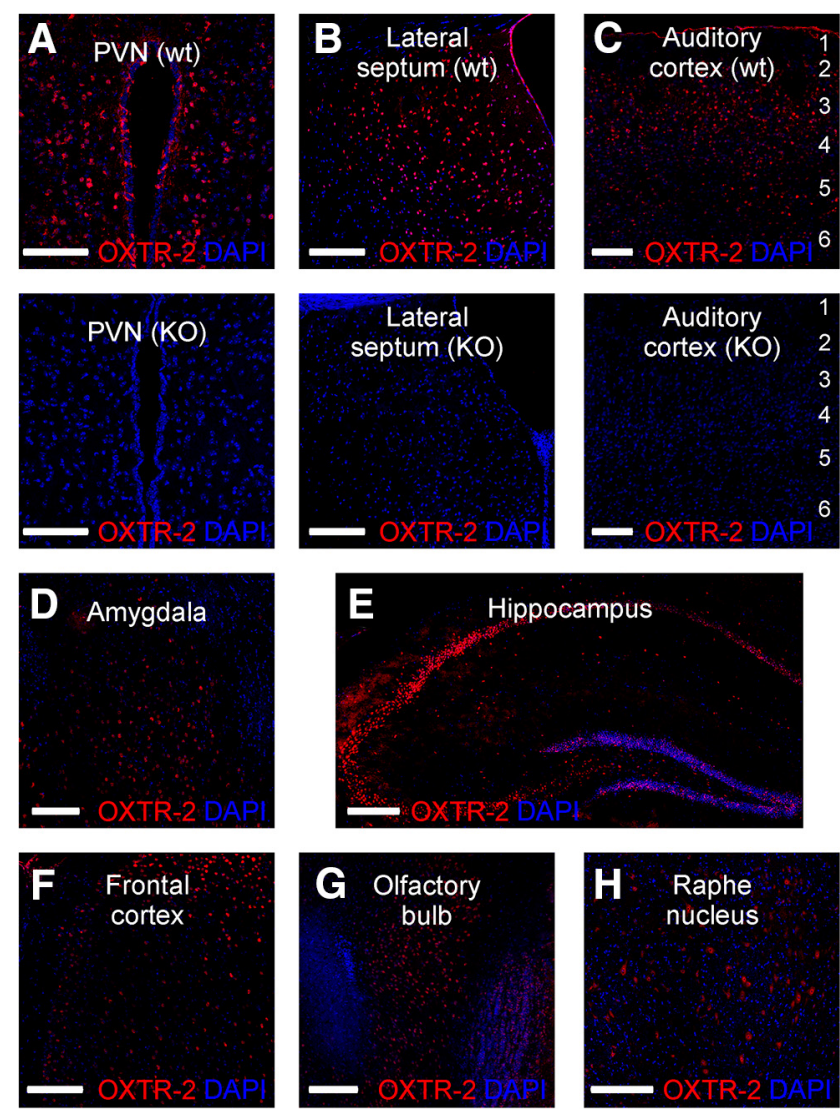

Figure 3. Expression of oxytocin receptors in virgin female mouse brain. $\boldsymbol{A}, 0 \mathrm{xyt}$ tocin receptor immunostaining in PVN with 0XTR-2 imaged at 20×. Red, OXTR-2; blue, DAPI. Scale bar, 100 $\mu \mathrm{m}$. Top, Wild-type (wt). Bottom, Oxytocin receptor knock-out animal (KO). Immunostaining with OXTR-2 did not detect receptors in oxytocin receptor knock-out animals. B, OXTR-2 immunostaining in lateral septum of wild-type (top) and knock-out animal (bottom) imaged at $10 \times$. Scale bar, $150 \mu \mathrm{m}$. C, Left auditory cortex of wild-type (top) and knock-out animal (bottom) imaged at $10 \times$. Scale bar, $100 \mu \mathrm{m}$. D, Amygdala imaged at $20 \times$. Scale bar, $100 \mu \mathrm{m}$. $\boldsymbol{E}$, Hippocampus imaged at $10 \times$. Scale bar, $500 \mu \mathrm{m}$. F, Frontal cortex imaged at $20 \times$. Scale bar, $150 \mu \mathrm{m}$. G, Olfactory bulb imaged at $10 \times$. Scale bar, $150 \mu \mathrm{m}$. $\boldsymbol{H}$, Median raphe nucleus imaged at $20 \times$. Scale bar, $150 \mu \mathrm{m}$.

Our initial analysis indicated that all four antisera were positive. We then focused on OXTR-2, which had the highest sensitivity of the four antibodies. First, we compared the immune and preimmune sera by immunoblotting with different amounts of pure target OXTR-2 peptide. No reactivity was observed in the preimmune bleeds, but higher levels of reactivity were observed with increasing amounts of OXTR-2 (Fig. 2A). We then used HEK293T cells transfected with OXTR-IRES-Venus CDNA to express oxytocin receptors and the Venus YFP variant in the same cells (Nagai et al., 2002; Yoshida et al., 2009). In Western blots from oxytocin-receptor-expressing HEK cells, we observed a protein band at $43 \mathrm{kDa}$ that corresponded to the expected molecular weight of the mouse oxytocin receptor (Fig. 2B, "OTR"). In contrast, that band was not present in untransfected control cells (Fig. 2B, “C”). Oxytocin-receptor-expressing HEK cells were also immunostained with OXTR-2 and cells were colabeled for both OXTR-2 and Venus (Fig. 2C).

We then examined OXTR-2 immunofluorescence in tissue from wild-type versus oxytocin receptor knock-out mice (Nishimori et al., 1996). Positive labeling was detected in wild-type virgin female uterine tissue (Fig. 2D) and brain (Fig. 3). In contrast, no labeling was observed in oxytocin receptor knock-out mice anywhere in the brain or other tissues such as uterus (Fig. 
A

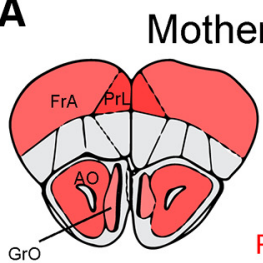

Gro
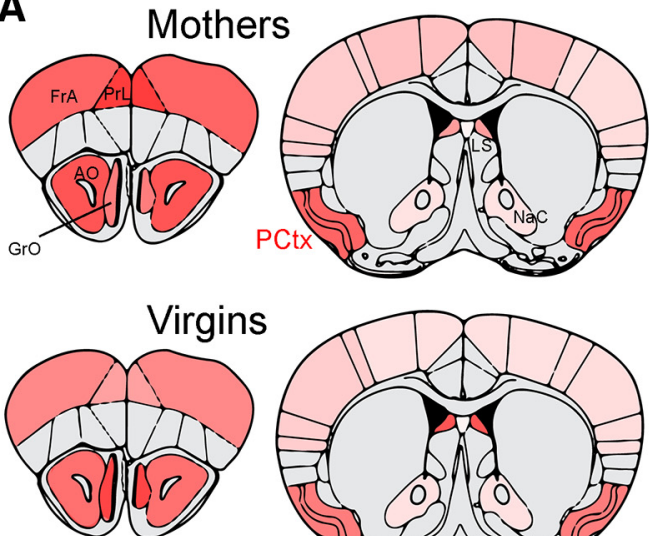

Left Right

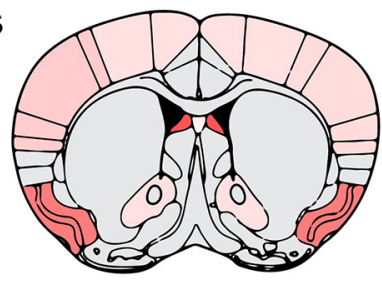

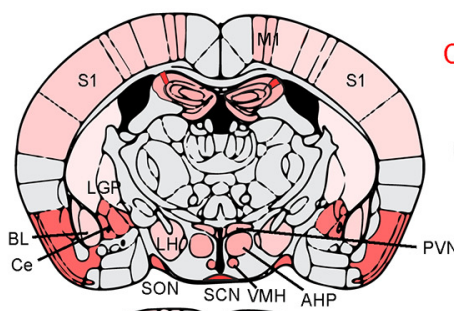

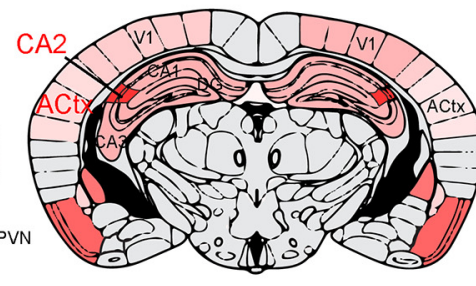

OXTR-2 staining
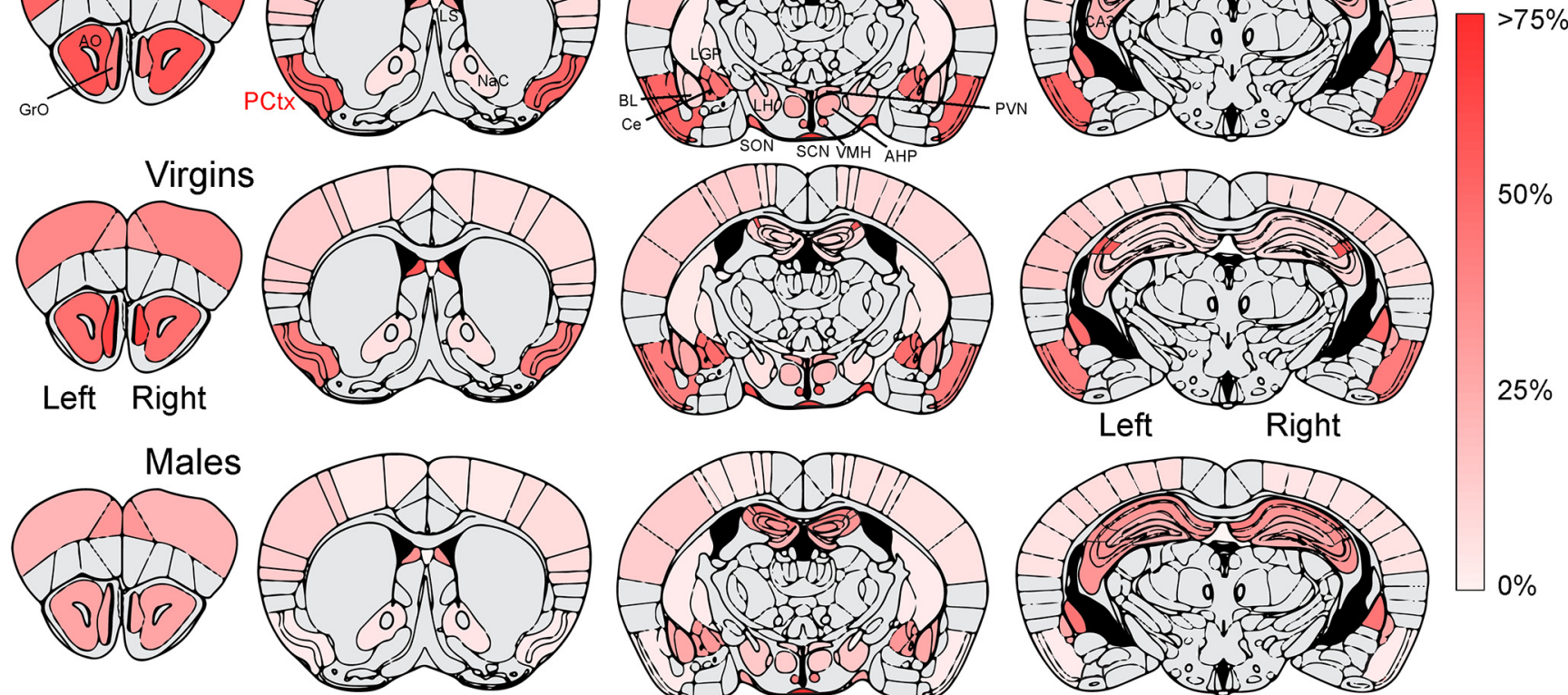

$50 \%$
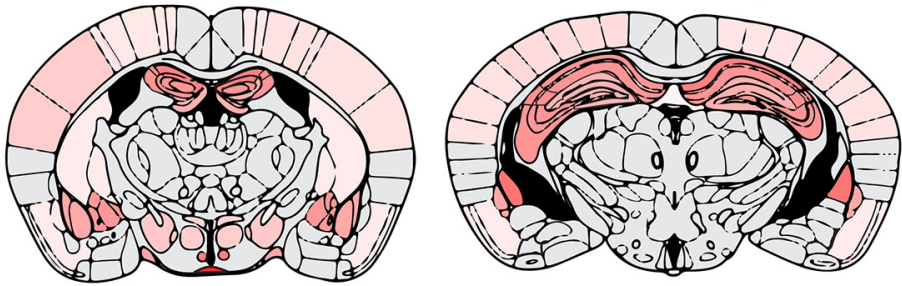

$25 \%$

D

B

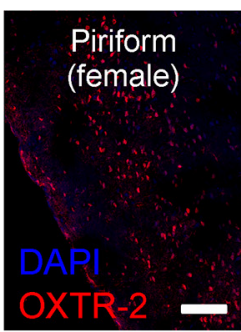

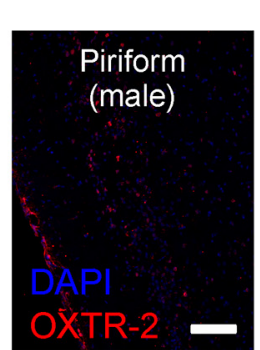

C

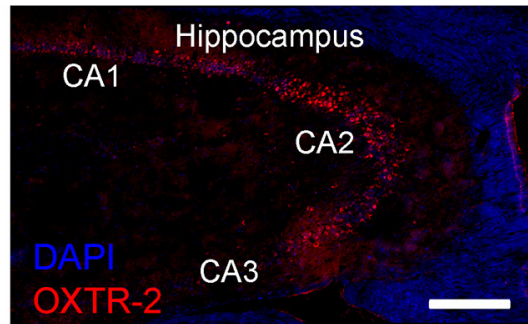

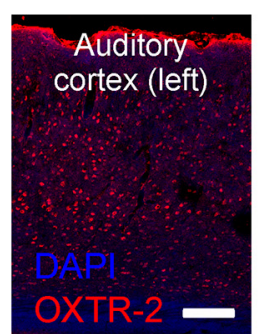

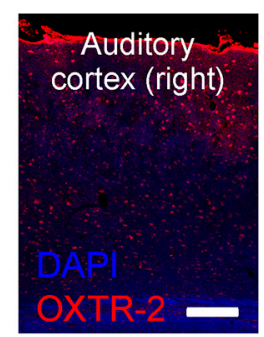

Figure 4. OXTR-2 expression profile in the brain. $\boldsymbol{A}$, Schematics summarizing OXTR-2 expression in mothers, virgin females, and males. Shown are four anterior-posterior coronal sections (from left: bregma $2.7 \mathrm{~mm}$, interaural $6.5 \mathrm{~mm}$; bregma $0.7 \mathrm{~mm}$, interaural $4.5 \mathrm{~mm}$; bregma $-1.1 \mathrm{~mm}$, interaural $2.7 \mathrm{~mm}$; and bregma $-2.3 \mathrm{~mm}$, interaural $1.5 \mathrm{~mm}$ ). Color indicates percentage of DAPI-positive cells that were 0XTR-2 + per region. Brain regions identified and quantified in Table 1: auditory cortex (ACtx), anterior hypothalamus (AHP), basolateral amygdaloid nucleus (BL), central amygdaloid nucleus (Ce), anterior olfactory nucleus (A0), bed nucleus of stria terminalis (BST), hippocampal areas CA1-CA3, dentate gyrus (DG), frontal association cortex (FrA), globus pallidus (LGP), granular cell layer of the olfactory bulb (GrO), lateral hypothalamic area (LH), right lateral septum (LS), motor cortex (M1), nucleus accumbens core (NaC), piriform cortex (PCtx), prelimbic cortex (PrL), paraventricular nucleus of hypothalamus (PVN), median raphe (RN), somatosensory cortex (S1), suprachiasmatic nucleus (SCN), supraoptic nucleus of hypothalamus (SON), visual cortex (V1), and ventromedial hypothalamic nucleus (VMH). Gray areas may have expressed oxytocin receptors but were not quantified here. B, OXTR-2 immunostaining in piriform cortex of female (left) and male (right) imaged at 10X. Note more 0XTR-2+ cells in females. Scale bar, $100 \mu \mathrm{m}$. C, 0XTR-2 immunostaining of virgin female hippocampus imaged at 20X. Scale bar, 200 $\mu \mathrm{m} . \boldsymbol{D}, 0$ XTR-2 immunostaining in left auditory cortex (left) and right auditory cortex (right) of virgin female imaged at 20X. Note more staining in left auditory cortex. Scale bar, $100 \mu \mathrm{m}$.

2D), hypothalamic PVN (Fig. 3A), lateral septum (Fig. 3B), and neocortex (Fig. 3C). Finally, preadsorption of the OXTR-2 antibody with OXTR-2 pure peptide abolished the immunoreactivity observed with antibody alone in wild-type cortex (Fig. 2E). These experiments demonstrate that the OXTR-2 antibody is highly specific for the mouse oxytocin receptor and that the antibody binds to the target epitope sequence on the oxytocin receptor.

Oxytocin receptor expression in adult mouse brain

Next, we used OXTR-2 antibodies to examine the expression patterns of oxytocin receptors in female virgin mice (Fig. 3) and compared receptor expression to mother animals and males (Fig. 4). Oxytocin receptors were expressed at various cell densities throughout the brain. We quantified expression levels in 29 different brain regions of experienced mother mice, pup-naive adult virgin females, and adult males (Table 1), including hypothalamus (Fig. 3A), neocortical regions such as piriform and auditory cortex (Fig. 3C), amygdala (Fig. 3D), subregions of the hip- pocampus (Fig. 3E), frontal cortex (Fig. $3 F$ ), olfactory bulb (Fig. $3 G$ ), and the median raphe nucleus (Fig. $3 H$ ). These regions were chosen based on their importance in social behavior (Yoshida et al., 2009; Nakajima et al., 2014; Rilling and Young, 2014). Schematics in Figure $4 A$ summarize the mean percentages of OXTR-2+ cells in mothers, virgins, and males relative to total cell counts for each area detected with DAPI nuclear stain, but it is important to note that receptor expression in some brain areas could be somewhat variable.

Our initial characterization showed that oxytocin receptors were expressed throughout the brains of female and male mice to varying degrees (Table 1) and the expression level was similar across the estrous cycle in virgin female auditory cortex or PVN $(p>0.4$ between estrous and proestrous, Student's unpaired two-tailed $t$ test, $n=3$ animals in each state). Quantification of oxytocin receptor expression revealed three obvious differences in the patterns of expression in adult mice. First, piriform cortex had more OXTR-2+ cells in females than in males (Fig. $4 B$, 
Table 1. Comparison of OXTR-2 labeling in adult mouse brain of mothers, virgin females, and males

\begin{tabular}{|c|c|c|c|}
\hline Brain region & Mothers & Virgin females & Males \\
\hline ACtx left (auditory cortex) & $20.8 \pm 3.5 \%$ & $26.5 \pm 2.3 \%$ & $18.9 \pm 2.1 \%$ \\
\hline ACtx right (auditory cortex) & $15.6 \pm 3.4 \%$ & $20.6 \pm 3.0 \%$ & $18.8 \pm 2.6 \%$ \\
\hline AHP (anterior hypothalamus) & $32.7 \pm 8.9 \%$ & $28.6 \pm 9.8 \%$ & $25.1 \pm 7.3 \%$ \\
\hline BL (basolateral amygdaloid nucleus) & $23.4 \pm 5.6 \%$ & $34.4 \pm 5.8 \%$ & $33.5 \pm 11.5 \%$ \\
\hline Ce (central amygdaloid nucleus) & $46.9 \pm 9.7 \%$ & $49.2 \pm 6.6 \%$ & $37.6 \pm 5.5 \%$ \\
\hline $\mathrm{A} 0$ (anterior olfactory nucleus) & $55.2 \pm 3 \%$ & $48.0 \pm 3.2 \%$ & $34.8 \pm 11 \%$ \\
\hline BST (bed nucleus of stria terminalis) & $24.7 \pm 10 \%$ & $42.2 \pm 7.2 \%$ & $31.5 \pm 17.1 \%$ \\
\hline CA1 (hippocampus) & $32 \pm 3.7 \%$ & $22.8 \pm 6.5 \%$ & $44.5 \pm 9.6 \%$ \\
\hline CA2 (hippocampus) & $62.6 \pm 4.3 \%$ & $52.8 \pm 5.9 \%$ & $39.8 \pm 11.9 \%$ \\
\hline CA3 (hippocampus) & $33.3 \pm 3.6 \%$ & $23.3 \pm 7.5 \%$ & $38.6 \pm 16.3 \%$ \\
\hline DG (dentate gyrus of hippocampus) & $30.8 \pm 9.7 \%$ & $20.8 \pm 5.6 \%$ & $31.8 \pm 5.5 \%$ \\
\hline FrA (frontal association cortex) & $51.2 \pm 5 \%$ & $42.4 \pm 11.6 \%$ & $30.9 \pm 6.7 \%$ \\
\hline LGP (globus pallidus) & $9.5 \pm 3.5 \%$ & $13 \pm 2.9 \%$ & $10.2 \pm 2.6 \%$ \\
\hline GrO (granular cell layer of the olfactory bulb) & $45.3 \pm 4.2 \%$ & $59.4 \pm 12.2 \%$ & $34.2 \pm 13.3 \%$ \\
\hline LH (lateral hypothalamic area) & $25.5 \pm 4.1 \%$ & $18.0 \pm 5.4 \%$ & $26.5 \pm 19.4 \%$ \\
\hline LS (right lateral septum) & $37.3 \pm 6.7 \%$ & $55.2 \pm 9.7 \%$ & $40.1 \pm 7 \%$ \\
\hline M1 (right motor cortex) & $28.1 \pm 7 \%$ & $20.4 \pm 0.8 \%$ & $12.5 \pm 2.1 \%$ \\
\hline $\mathrm{NaC}$ (nucleus accumbens core) & $18.8 \pm 6.8 \%$ & $20.4 \pm 6.5 \%$ & $16.2 \pm 6.6 \%$ \\
\hline PCtx (piriform cortex) & $51.0 \pm 10.1 \%$ & $44.8 \pm 7.5 \%$ & $10.5 \pm 1.4 \%$ \\
\hline PrL (prelimbic cortex) & $60.8 \pm 9.7 \%$ & $36.4 \pm 8.3 \%$ & $37.9 \pm 13.2 \%$ \\
\hline PVN (paraventricular nucleus of hypothalamus) & $31.1 \pm 4.6 \%$ & $33.1 \pm 8.7 \%$ & $23.1 \pm 12.4 \%$ \\
\hline RN (median raphe) & $23.2 \pm 7.1 \%$ & $17.9 \pm 3.4 \%$ & $19.9 \pm 6.2 \%$ \\
\hline S1 left (somatosensory cortex) & $24.6 \pm 9.5 \%$ & $24.9 \pm 5.7 \%$ & $13.1 \pm 4.4 \%$ \\
\hline S1 right (somatosensory cortex) & $20.8 \pm 6.3 \%$ & $22.4 \pm 5.2 \%$ & $18.5 \pm 5.1 \%$ \\
\hline SCN (suprachiasmatic nucleus) & $61.8 \pm 6.7 \%$ & $60.2 \pm 6.1 \%$ & $64.9 \pm 4.8 \%$ \\
\hline SON (supraoptic nucleus of hypothalamus) & $57.1 \pm 4.1 \%$ & $55.8 \pm 8.6 \%$ & $35.4 \pm 19.8 \%$ \\
\hline V1 left (visual cortex) & $25.2 \pm 5.9 \%$ & $18.4 \pm 6.4 \%$ & $21.0 \pm 1.8 \%$ \\
\hline V1 right (visual cortex) & $30.5 \pm 5.9 \%$ & $20.5 \pm 6.2 \%$ & $16.0 \pm 3.2 \%$ \\
\hline VMH (ventromedial hypothalamic nucleus) & $42 \pm 11.8 \%$ & $53.1 \pm 12.1 \%$ & $44.3 \pm 8.1 \%$ \\
\hline
\end{tabular}

Listed are the percentages of the 0XTR-2-labeled DAPl-positive cells (for all regions except auditory cortex: $n=4$ for mothers and virgin females, $n=3$ for males; for auditory cortex, $n=7$ for mothers, $n=9$ for virgin females, $n=5$ for males).

$p<0.03$, ANOVA with Bonferroni correction for multiple comparisons). Piriform cortex is an olfactory area believed to be important for learned odor associations and several forms of social behavior (Haberly and Bower, 1989; Richter et al., 2005; Cohen et al., 2015). Second, hippocampal CA2 in females had more OXTR-2 + cells than in other regions of the hippocampal formation (Fig. $4 C, p<0.01$ ). This hippocampal subregion is also thought to be especially sensitive to peptidergic modulation and involved in social memory formation (Hitti and Siegelbaum, 2014; Pagani et al., 2015). Finally, left auditory cortex in females had more OXTR-2+ cells than in right auditory cortex from the same females (Fig. $4 D, p<0.002$, Student's paired two-tailed $t$ test), although this lateralization was not observed in males $(p>0.9)$. Collectively, these areas represent a distributed network for social cognition related to mouse maternal behavior, particularly in terms of auditory, olfactory, and spatial memory.

These observations then led us to investigate whether cortical receptor expression was lateralized more generally throughout the temporal lobe in which the auditory cortex is located or perhaps in other sensory systems as well. However, this was not the case. Across animals, there was no clear left/right asymmetry of OXTR-2 immunoreactivity in primary somatosensory barrel cortex $(p>0.4)$ or visual cortex $(p>0.2)$, although it is important to note that we did not test animals behaviorally to control for paw preference or other forms of functional lateralization (Biddle and Eales, 1996). We also did not detect significant left lateralization within other temporal areas surrounding core auditory cortex either dorsal $(p>0.1)$ or ventral $(p>0.7)$ from the core regions. These findings indicate that, although oxytocin may act throughout the brain, there are specific areas related to ma- ternal behaviors that may be especially sensitive to oxytocinergic modulation in female mice beyond the hypothalamus: hippocampal CA2, piriform cortex, and left auditory cortex. Modulation and plasticity in these areas may be especially important for recognition of infant vocalizations, scents, and locations.

\section{Oxytocinergic axonal projections}

How do these patterns of oxytocin receptor expression relate to axonal projections from oxytocin-releasing neurons of the PVN? We examined oxytocinergic axons in oxytocin-IRES-Cre (OxtIRES-Cre) mice (Irani et al., 2010; Wu et al., 2012) expressing YFP specifically in PVN oxytocin neurons via stereotaxic injection of a Cre-dependent adeno-associated virus (pAAV5-Efla-DIOChETA-EYFP). We counted YFP+ axon segments and putative axon terminals in the same brain areas of different virgin female mice examined for oxytocin receptor expression.

In general, there was little correspondence between the percentage of OXTR-2+ cells and the density of YFP+ axon segments and terminals in the cortex and throughout the rest of the brain, although there was some interesting regional heterogeneity (Fig. 5). For example, sections of virgin female left auditory cortex expressed more oxytocin receptors than visual cortex (Table 1), but we observed a comparable number of oxytocinergic fibers across different cortical areas of virgin female Oxt-IRESCre mice (Fig. 5A-C, $n=7$ animals, $p>0.3$, ANOVA). We also found that hippocampal CA1 and CA2 had substantially more $\mathrm{YFP}+$ axons than CA3 and the dentate gyrus from the same animals (Fig. 5D,E, $p<0.05$ ). Over all brain regions examined, however, there was not a significant correlation between OXTR-2 expression and oxytocinergic axon abundance (Fig. 5F, r: 0.32, $p>0.1$ ). As we previously reported in a smaller subset of animals 

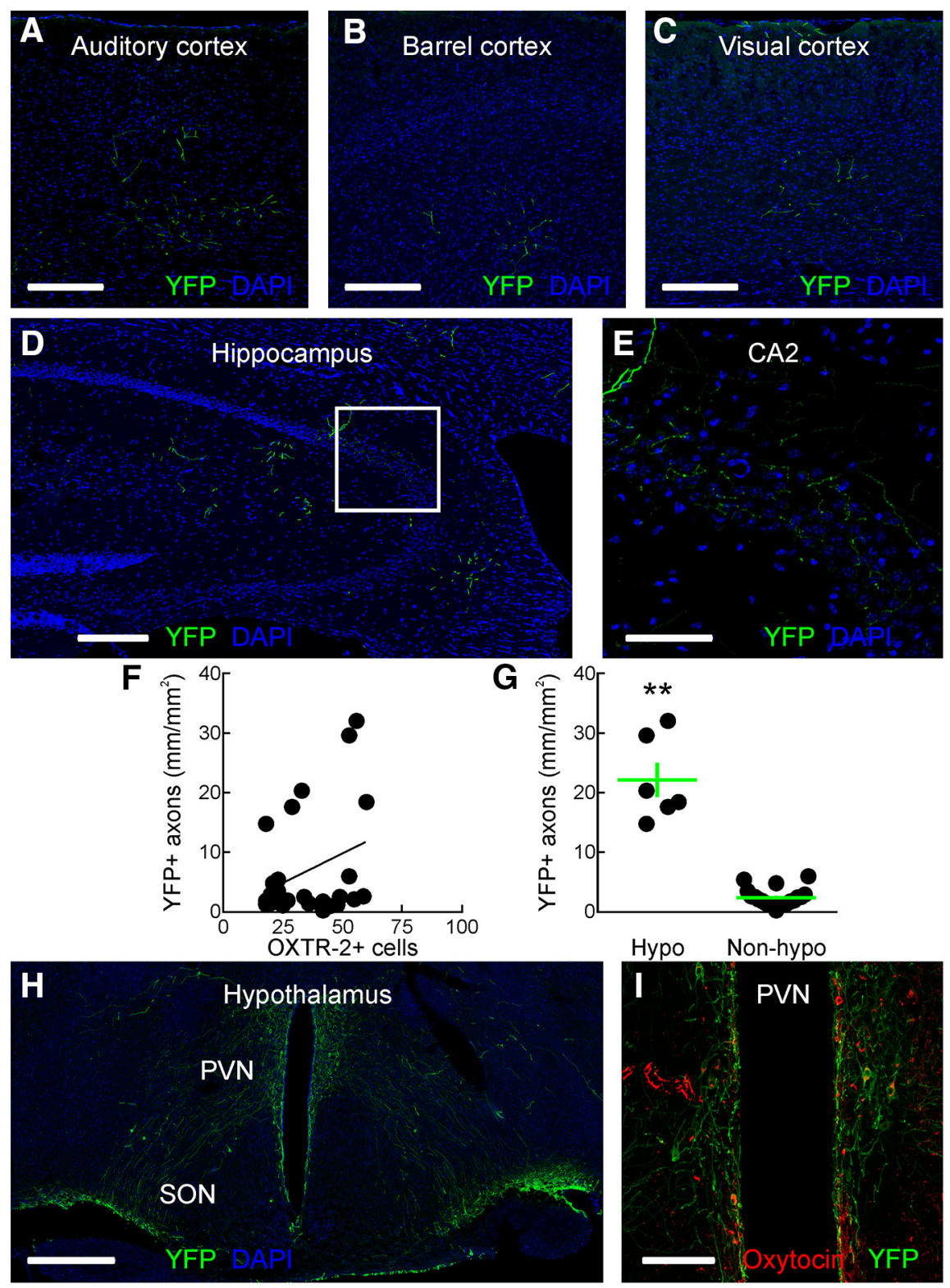

Figure 5. Oxytocinergic axonal projections from PVN. $A$, Section of virgin female left auditory cortex from Oxt-IRES-Cre animal expressing YFP via AAV (pAAV-5Ef1a-DI0 ChETA-EYFP) stereotaxically injected into left PVN immunostained with antibodies to YFP and imaged at $10 \times$. Green, YFP + axons; blue, DAPI. Scale bar, $200 \mu \mathrm{m}$. B, Section of virgin female barrel cortex imaged at 10X. Scale bar, $200 \mu \mathrm{m}$. C, Section of virgin female primary visual cortex imaged at $10 \times$. Scale bar, $200 \mu \mathrm{m}$. D, Section of virgin female hippocampus imaged at $10 \times$. White box indicates section shown in $\boldsymbol{E}$. Scale bar, $200 \mu \mathrm{m}$. $\boldsymbol{E}$, Magnification of CA2 from section shown in $\boldsymbol{D}$ imaged at $20 \times$ showing higher number of axon segments in that area. Scale bar, $100 \mu \mathrm{m}$. $\boldsymbol{F}$, Nonsignificant correlation between percentages of OXTR-2 + cells and axon segment densities across 26 brain regions $(r=0.32, p>0.1)$. OXTR-2+ cells quantified in four wild-type virgin female mice; YFP + axon density quantified in seven Oxt-IRES-Cre virgin female mice infected with Cre-inducible pAAV5-Ef1 $\alpha$ :-DI0-ChETA-EYFP virus injected into PVN. G, Comparison of axon segment density in six hypothalamic areas (Hypo) versus 20 nonhypothalamic brain areas (Nonhypo). Hypothalamic areas had significantly more YFP + axon segments (hypothalamus had $933.1 \pm 120.9 \%$ YFP + axon segments compared with mean axon length in nonhypothalamic regions, $n=7$ virgin female mice, $p<0.001$, Student's unpaired two-tailed $t$ test). Statistics and error bars are means \pm SEM. ${ }^{* *} p<0.01$. H, Section of virgin female hypothalamus imaged at $10 \times$. Scale bar, $400 \mu \mathrm{m}$. I, Magnification of PVN imaged at $20 \times$ showing costaining with antibody to oxytocin peptide (red). Scale bar, $100 \mu \mathrm{m}$.

(Marlin et al., 2015), there was no obvious lateralization of axon segments in left versus right virgin female auditory cortex (left segments: $1.9 \pm 0.5 \mathrm{~mm}$ axon $/ \mathrm{mm}^{2}$ tissue; right segments: $1.5 \pm$ $0.5 \mathrm{~mm} / \mathrm{mm}^{2}, n=7$ mice, $p>0.1$, Student's paired two-tailed $t$ test).

Hypothalamic nuclei expressed the highest densities of oxytocinergic fibers (including but not limited to the PVN and SON), almost 10 times greater than the rest of the brain (Fig. $5 G, p<0.001$ for hypothalamic regions compared with nonhypothalamic regions). We observed what appeared to be direct oxytocin fibers between PVN and SON (Fig. 5H). Using an antibody to oxytocin peptide, we confirmed that these PVN cells and projections were oxytocinergic because they were costained for oxytocin and YFP (Fig. $5 I$ ). Therefore, neural processing may be coordinated in some manner between these two nuclei by direct interactions mediated by oxytocin.

\section{Subcellular localization of cortical oxytocin receptor expression}

We took advantage of the specificity of the OXTR-2 antibody to examine the subcellular localization of oxytocin receptors. We used electron microscopy to examine tissue sections of virgin female mice $(\mathrm{Ne}$ delescu et al., 2010; Waters et al., 2015), sampling from the auditory cortex of both wild-type and oxytocin receptor knockout animals to quantify the relative amount of OXTR-2 labeling in various subcellular compartments.

We observed OXTR-2 labeling throughout cortical tissue sections at low to moderate levels (Fig. 6). Oxytocin receptors were found at putative excitatory synapses, both at presynaptic terminals (Fig. $6 A, F, p<10^{-4}$, Fisher's two-tailed exact test) opposed to PSDs and also at PSDs themselves (Fig. $6 B, D, F, p<10^{-4}$ ). OXTR-2 labeling was also found at inhibitory synapses located both on dendritic shafts and perisomatically (Fig. 6C,F, $p<$ 0.01 ), as well as preterminal axon segments and glial cells (Fig. 6D,E,G, $p<$ $10^{-4}$ for axonal labeling, $p<0.004$ for glial labeling). However, we did not detect significant labeling within dendrites (Fig. $6 G, p>0.1)$. Inhibitory synapse expression is interesting given recent studies by us (Marlin et al., 2015) and others (Owen et al., 2013) showing that oxytocin modulates GABAergic transmission in neocortical and hippocampal circuits. Moreover, oxytocin receptors are expressed predominantly by cortical interneurons (Nakajima et al., 2014; Marlin et al., 2015). These data suggest that oxytocin receptors are poised at GABAergic synapses to control inhibitory transmission, perhaps by multiple presynaptic and postsynaptic mechanisms.

\section{Development of cortical and thalamic oxytocin receptor expression}

An interesting set of studies has recently examined oxytocin modulation in the perinatal and postnatal rodent hippocampus, demonstrating that oxytocin can reduce the efficacy of GABAer- 
gic transmission as either an inhibitory (Owen et al., 2013) or excitatory (Tyzio et al., 2006; Tyzio et al., 2014) neurotransmitter. Therefore, we next investigated whether oxytocin receptors were expressed in the female mouse auditory thalamus and cortex at earlier ages and, if so, whether there were differences in the patterns of receptor expression early in life compared with adulthood.

We noticed that the spatiotemporal profile of OXTR-2+ expression in the auditory cortex differed over the first three postnatal weeks compared with adulthood (Fig. 7A-C). We quantified OXTR-2 expression and mRNA levels in the left and right medial geniculate body (the auditory thalamus; Fig. 7D, top) and auditory cortex (Fig. 7E, top). We observed changes in the number of OXTR-2+ cells with age. Expression began relatively high in the auditory thalamus during the first postnatal week and declined thereafter in a similar manner for both the left and right hemispheres (Fig. 7D, top, $p<10^{-4}$, ANOVA with Bonferroni correction for multiple comparisons). This pattern of protein expression was matched by a corresponding reduction in oxytocin receptor mRNA as measured with RNAseq over postnatal development after the high levels in the first postnatal week (Fig. 7D, bottom, $p<0.05$ ).

A different pattern was observed in the auditory cortex. Initially, expression and mRNA levels were both low during the first postnatal week, but then increased abruptly at week two, decreasing thereafter to moderate levels in adults (Fig. $7 E$, $p<10^{-4}$ for OXTR-2 expression, $p<$ 0.03 for mRNA). The second and third weeks are important stages for auditory cortical development, with hearing onset in rodents beginning around $\mathrm{P} 10$, the critical period for tonotopic map organization occurring over the next few days, and the development of excitatory-inhibitory balance progressing into the end of the third postnatal week (Dorrn et al., 2010; Barkat et al., 2011; Froemke and Jones, 2011).

Oxytocin receptor expression is lateralized in adult female mouse auditory cortex (Marlin et al., 2015), with 30\% more cells expressing these receptors within core auditory cortex (Fig. 4, Table 1). We found that this asymmetrical receptor expression was not present early in life, but emerged in the third postnatal week (Fig. 7F, top), even though receptor expression was highest overall during the second postnatal week (Fig. 7E, top). To examine the bi-
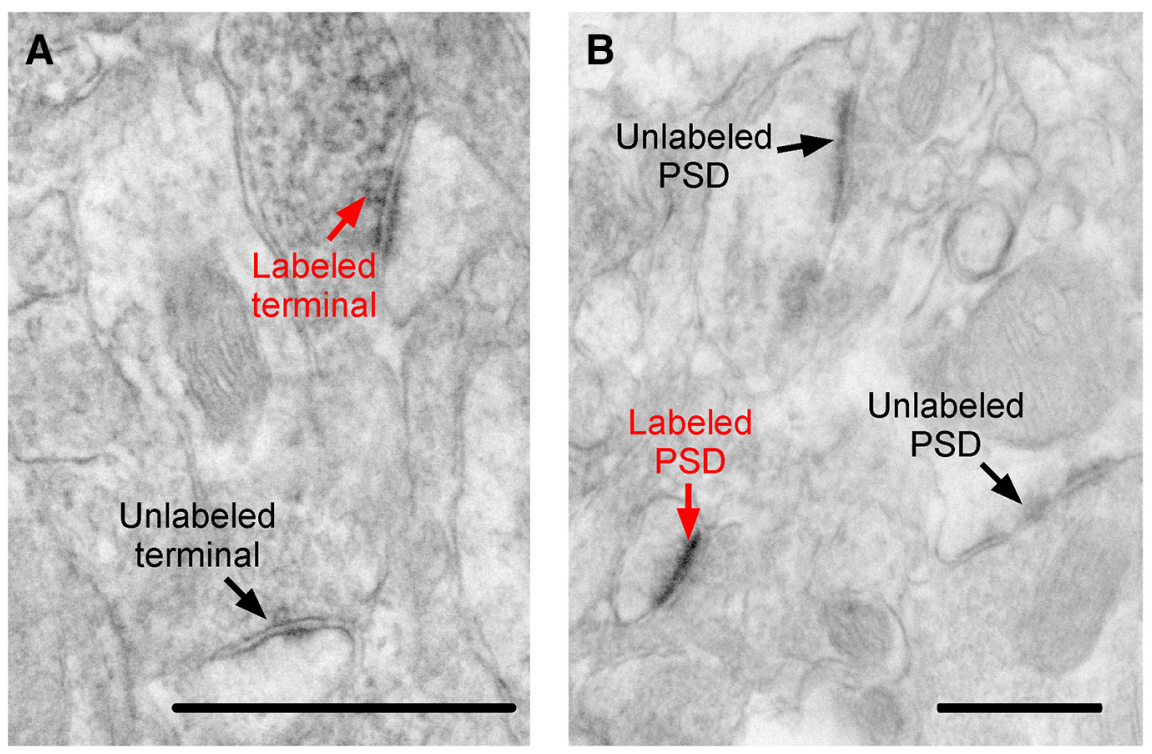

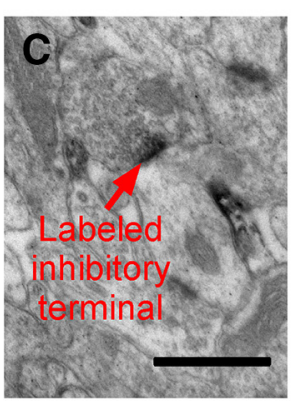

$\mathbf{F}$

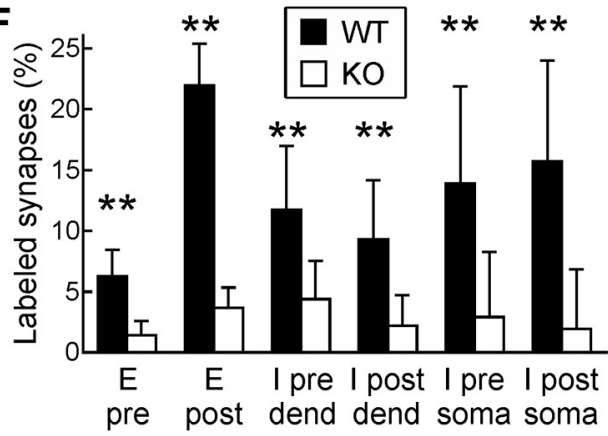

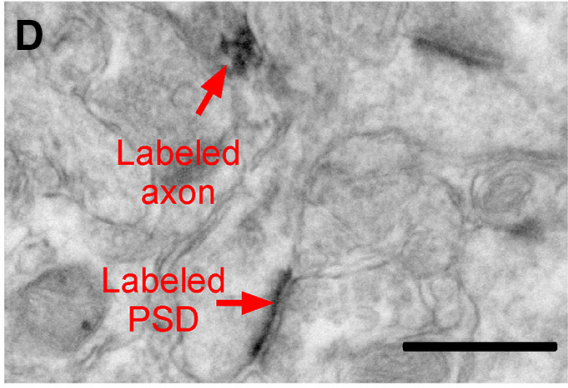

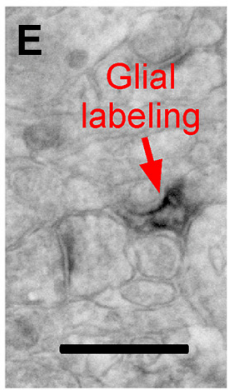

G

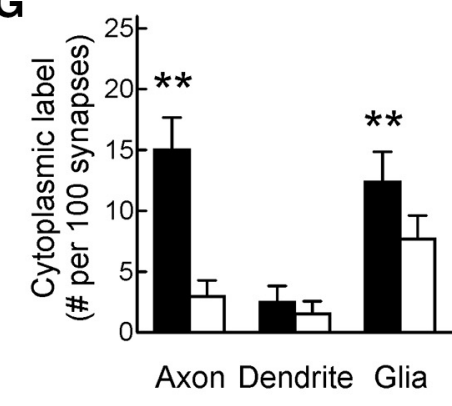

Figure 6. Subcellular localization of oxytocin receptors. $A, 0 x y$ tocin receptor immunoreactivity in the auditory cortex was revealed using HRP-DAB as the immunolabel and antibody dilution of 1:3500. Presynaptic immunolabeling was detected on axospinous asymmetric (presumably excitatory) synapses. The same axon formed another synapse below. At this portion of the axon, the presynaptic side was unlabeled. Scale bar, $500 \mathrm{~nm}$. $\boldsymbol{B}$, Three other putative excitatory synapses, one synapse with labeling over the PSD and two other unlabeled PSDs shown for comparison. Scale bar, $500 \mathrm{~nm}$. C, Example of labeled inhibitory terminal. Scale bar, $500 \mathrm{~nm}$. D, Cytoplasmic immunolabeling observed in an axon. A labeled PSD is also apparent. Scale bar, 500 $\mathrm{nm}$. $\boldsymbol{E}$, Cytoplasmic immunolabeling observed in a glial process (putative astrocyte). Scale bar, $500 \mathrm{~nm}$. $\boldsymbol{F}$, Summary of synaptic location of OXTR-2 in four wild-type (WT, filled bars) and four oxytocin receptor knock-out animals (K0, open bars). Significant labeling was detected at putative excitatory presynaptic terminals (E pre, $6.3 \pm 2.2 \%$ WT synapses vs $1.4 \pm 1.2 \%$ KO synapses, $p<10^{-4}$, Fisher's two-tailed exact test) and postsynaptic spines (E post, $22.0 \pm 3.4 \%$ WT synapses vs $3.7 \pm 1.7 \%$ KO synapses, $p<10^{-4}$ ), putative inhibitory synapses onto dendritic shafts (I pre dend, $11.8 \pm 5.2 \%$ WT synapses vs $4.4 \pm 3.1 \%$ K0 synapses, $p<0.008$; I post dend, $9.3 \pm 4.9 \%$ WT synapses vs $2.2 \pm 2.5 \%$ K0 synapses, $p<0.0008$ ), and putative inhibitory synapses onto cell bodies (I pre soma, $13.9 \pm 8.3 \%$ WT synapses vs $2.9 \pm 5.4 \%$ KO synapses, $p<0.006$; I post soma, $15.7 \pm 8.3 \%$ WT synapses vs $1.9 \pm 4.9 \% \mathrm{~K} 0$ synapses, $p<0.0005)$. A total of 637 WT excitatory synapses, $706 \mathrm{KO}$ excitatory synapses, 312 WT inhibitory synapses, and $376 \mathrm{KO}$ inhibitory synapses were examined. Statistics and error bars are means $\pm 95 \%$ binomial confidence intervals. ${ }^{* *} p<0.01$. G, Summary of cytoplasmic location of OXTR-2 in wild-type and oxytocin receptor knock-out animals. Labeled cytoplasmic segments were quantified relative to the total number of synapses counted ( 800 WT and 907 K0). Significant labeling was detected in the cytoplasm of putative axon segments ( $15.0 \pm 2.7 \%$ WT vs $3.0 \pm 1.3 \% \mathrm{KO}, p<10^{-4}$ ) and glial cells $(12.4 \pm 2.5 \%$ WT vs $7.7 \pm 1.9 \%$ K0, $p<0.004)$, but not dendrites $(2.5 \pm 1.3 \%$ WT vs $1.5 \pm 1.0 \%$ K0, $p>0.1)$. Statistics and error bars are means $\pm 95 \%$ binomial confidence intervals. 

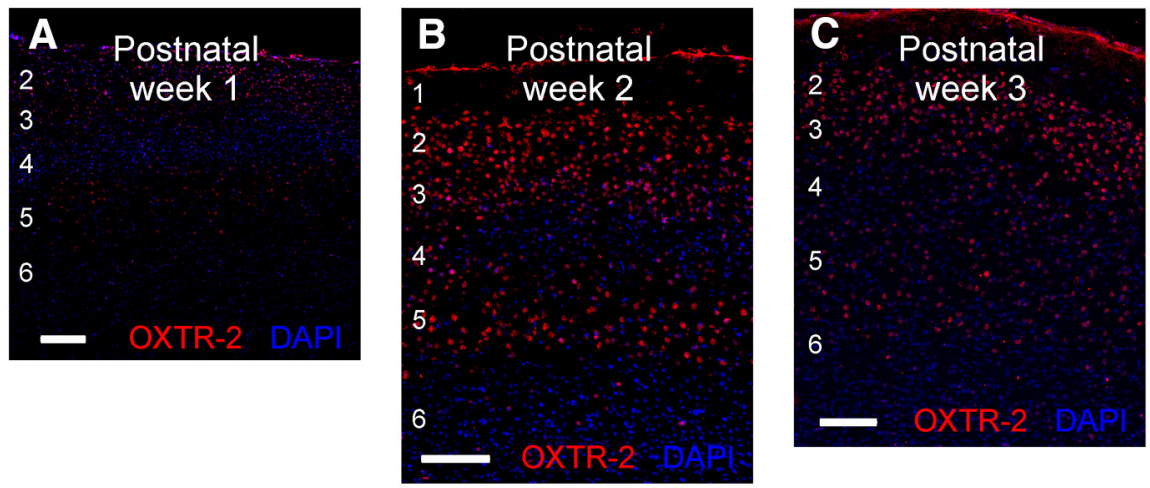

D

E
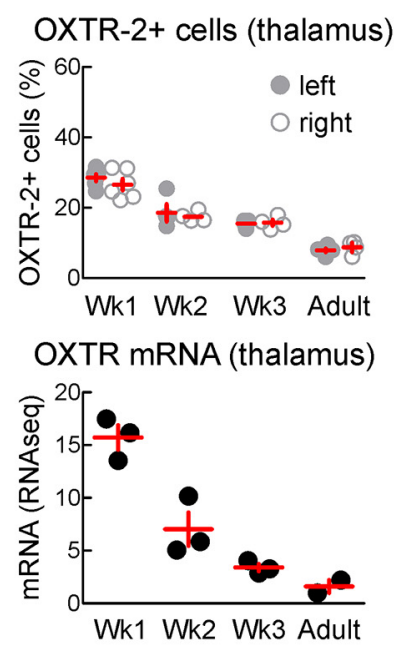

Figure 7. Development of auditory thalamocortical oxytocin receptor expression. $A, 0 X T R-2$ labeling in female left auditory cortex of postnatal week 1 mouse. Note lower level of expression in layer 4 compared with other layers. Scale bar, $100 \mu \mathrm{m}$. $\boldsymbol{B}$, OXTR-2 labeling in female left auditory cortex of postnatal week 2 mouse. Scale bar, $100 \mu \mathrm{m}$. C, OXTR-2 labeling in female left auditory cortex of postnatal week 3 mouse. Scale bar, $100 \mu \mathrm{m}$. D, Summary of OXTR-2-labeled cells (top) and OXTR mRNA measured with RNAseq (bottom) at different postnatal weeks (Wk) in auditory thalamus. The first postnatal week had the highest amount of thalamic OXTR-2 expression ( $n=18$ animals, $4-6$ animals/age; $p<10^{-4}$, ANOVA with Bonferroni correction for multiple comparisons) and mRNA level ( $n=11$ animals, $2-3$ animals/age; $p<0.05$ ). Filled symbols, tissue from left hemisphere; open symbols, right hemisphere. Red lines and error bars are means \pm SEM. $\boldsymbol{E}$, Summary of OXTR-2-labeled cells (top) and OXTR mRNA (bottom) at different ages in auditory cortex. The second and third postnatal weeks had the highest amount of cortical OXTR-2 expression ( $n=21$ animals, $4-7$ animals/age; $p<10^{-4}$ ) and mRNA level ( $n=12$ animals, 3 animals/age; $p<0.03$ ). $\boldsymbol{F}$, Summary of oxytocin receptor lateralization in left versus right virgin female auditory cortex. Top, 0XTR-2 expression is higher in left auditory cortex than in right auditory cortex from the same animals during and after postnatal week 3 ( $n=11$ virgin females, $p<0.0006$, Student's paired two-tailed $t$ test), but not earlier during postnatal weeks $1-2$ ( $n=10$ virgin females, $p>0.2$ ). Bottom, oxytocin receptor mRNA (measured with RT-PCR relative to ribophorin mRNA expression) is higher in left auditory cortex than in right auditory cortex from the same adult virgin females (left auditory cortex expressed $112.4 \pm 5.4 \%$ mRNA as right auditory cortex, $n=9, p<0.04$, Student's paired two-tailed $t$ test). 0xytocin receptor mRNA was not detected in oxytocin receptor knock-out mice (KO, $n=3$ virgin females). Statistics and error bars are means \pm SEM. ${ }^{*} p<0.05$.

ological basis of this asymmetry, we quantified oxytocin receptor mRNA transcript levels from left versus right female adult auditory cortex. We observed a subtle but significant difference in the amount of transcript between the left and right hemispheres, with more oxytocin receptor mRNA on the left side than on the right of individual animals (Fig. $7 F$, bottom, $p<0.05$, Student's paired two-tailed $t$ test). We did not detect any oxytocin receptor mRNA in auditory cortex tissue from oxytocin receptor knock-out mice (Fig. 7F, bottom, "KO"). Therefore, the asymmetry in oxytocin receptors appears to be prepatterned and is likely driven by transcriptional regulation or other genetic factors rather than posttranslational mechanisms. These results also support a close coupling between mRNA amount and protein amount of oxytocin receptors in the mouse brain across multiple areas and ages.

We also noticed that oxytocin receptor expression was lower in layer 4 compared with superficial and deeper layers (Fig. $7 A-C$ ). The number of cells expressing oxytocin receptors in layer 4 was significantly lower from receptor expression in other layers at all ages, except compared with layers 5-6 in adult animals (Fig. 8). During early postnatal development, when thalamic levels are high but layer 4 levels are low, oxytocin might independently modulate thalamic and intracortical circuits. Thereafter, the oxytocin-receptor-expressing cells might mature along a layer-specific program, first in the superficial layers and then in deep layers, before expression occurs or cells mature within layer 4 .

\section{Modulation of synaptic responses by oxytocin}

What are the functional consequences of oxytocin signaling in the CNS? We investigated how oxytocin might modulate synaptic transmission in the adult brain, specifically in three areas thought to be important for social communication: left auditory cortex (Fig. 9A), piriform cortex (Fig. 9B), and PVN (Fig. 9C). We made whole-cell recordings in brain slices of virgin female mice from these regions. First, we measured IPSCs in voltage-clamp mode at a depolarized holding potential, monitoring inhibitory synaptic responses evoked with an extracellular stimulation electrode placed near the recorded cell. After monitoring baseline IPSCs for several minutes, oxytocin was washed into the bath for $\sim 5 \mathrm{~min}$ and responses measured during and after oxytocin application.

In each region, oxytocin consistently reduced inhibition (Fig. 9D-F), confirming and extending previous studies in the auditory cortex and hippocampus (Owen et al., 2013; Marlin et al., 2015). We used $1 \mu \mathrm{M}$ oxytocin for recordings from virgin female left auditory cortex (Fig. $9 A, D$ ) and $5 \mu \mathrm{M}$ oxytocin for recordings from virgin female piriform cortex (Fig. 9B,E) or PVN (Fig. 9C,F). These concentrations were chosen based on measurements of dose-response relations for each region, where 1-5 $\mu \mathrm{M}$ oxytocin led to the maximal amount of disinhibition in auditory cortex (Fig. 9G). Higher concentrations were required to reduce inhibition by a comparable degree in piriform cortex (Fig. 9H) and PVN (Fig. 9I), with 5-10 $\mu \mathrm{M}$ oxytocin reducing inhibition by a similar level in these two regions. Note that ACSF alone ( $0 \mu \mathrm{M}$ oxytocin $) \mathrm{did}$ not affect IPSC amplitudes (Fig. 9G-I). Optogenetic release of 

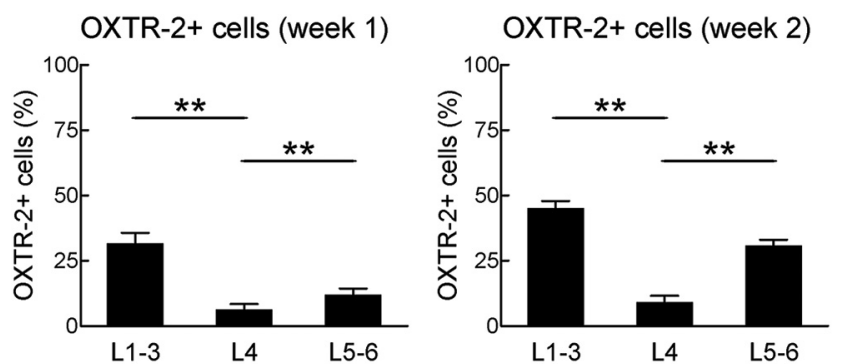

OXTR-2+ cells (week 3)
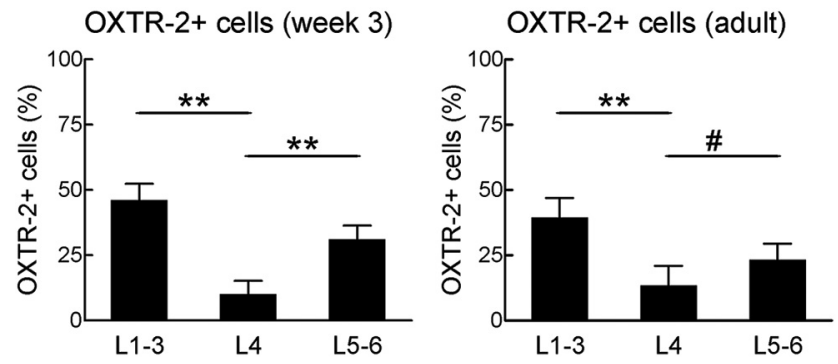

Figure 8. Laminar expression of OXTR-2 in auditory cortex. Shown is the percentage of OXTR-2-labeled cells in auditory cortex at four different postnatal ages, in superficial layers 1-3, in layer 4 , and deep layers $5-6$. Layer 4 contains significantly fewer 0 XTR- $2+$ cells $\left(^{* *} p<\right.$ $10^{-4}$ compared with layers $1-3$ and layers $5-6$, Fisher's exact two-tailed $t$ test corrected for multiple comparisons), except compared with layers $5-6$ in adult animals $(\# p=0.09)$.

endogenous oxytocin in slices from Oxt-IRES-Cre animals also reduced IPSCs in each region in a comparable manner (Fig. 10).

In contrast to the robust and reliable disinhibition produced within 3-6 min by pharmacological treatment (Figs. 9, 11A) or optogenetic release of oxytocin (Figs. 10, 11A), excitatory responses onto the same cells were relatively unchanged during the first 3-6 min of the wash-in period (Fig. 11B). The disinhibitory effect of oxytocin was blocked by coapplication of a specific oxytocin receptor antagonist, OTA $(1 \mu \mathrm{M}$, Fig. $11 C)$, indicating that these effects are mediated directly by oxytocin receptor activation and not cross-reactivity of oxytocin peptide with other types of receptors. In auditory cortex and PVN, the reduction of inhibition could be observed when excitatory synapses were blocked with DNQX and APV (Fig. 11D). In contrast, blocking excitation prevented oxytocinergic disinhibition in the piriform cortex (Fig. $11 D$ ), suggesting that the mechanism of oxytocin modulation may be distinct in different brain areas, although the functional consequences may be similar.

We also assessed whether oxytocin wash-in affected spontaneous, ongoing EPSCs and IPSCs in these three regions. Strikingly, spontaneous rates of EPSCs and IPSCs were each increased in auditory cortex, piriform cortex, and PVN, with spontaneous inhibitory rates more than quadrupling in piriform cortex (Fig. $11 E, F)$, similar to the effects of oxytocin receptor agonist application in hippocampal slices (Owen et al., 2013). This increase in spontaneous rate occurred in the absence of significant changes to the mean spontaneous event amplitude (Fig. $11 E, G$ ). These data suggest that, in the auditory cortex and PVN, reduction in evoked inhibition might occur via presynaptic activation of oxytocin receptors on inhibitory terminals that serve to decrease GABAergic transmitter release, similar to the action of several other neuromodulators in mouse cortex (Kruglikov and Rudy, 2008). However, in piriform cortex, excitatory cells and synapses onto inhibitory cells might be affected by oxytocin, increasing inhibitory tone and hyperpolarization to reduce excitatory drive onto inhibitory cells.
Disinhibition can be effective for inducing long-term synaptic modifications in the auditory cortex (Froemke, 2015). Recently, we showed that oxytocin could transform responses in female virgin auditory cortex, increasing the number of spikes evoked by infant distress vocalizations (Marlin et al., 2015). To examine the mechanisms and specificity of such cortical plasticity directly, we recorded from auditory cortical neurons in brain slices (Fig. 12) and in vivo (Fig. 13). Our goal was to determine whether oxytocin modulation can help to induce long-term potentiation (LTP) of synaptic input and increase spiking output. We also wondered whether oxytocin modulation might only be specialized for modifying responses to pup calls and other kinds of vocalizations or if oxytocin might more generally affect cortical responses to any incoming stimulus.

Repetitive stimulation in the presence of oxytocin could reliably potentiate excitatory synapses. A recording from virgin female left auditory cortex in vitro is shown in Figure 12A. Initially, this neuron almost never fired spikes in response to synaptic stimulation. Although excitation was initially unaffected, oxytocin wash-in $(5 \mu \mathrm{M})$ led to a gradual increase in EPSPs over 10-20 min, which persisted long after oxytocin washout. In parallel, this cell began firing action potentials, eventually firing reliably on almost every trial. Similar effects were obtained with optogenetic release of endogenous oxytocin in slices made from Oxt-IRES-Cre animals virally expressing ChETA in oxytocin neurons. A recording is shown in Figure $12 B$ and the action of oxytocin on LTP induction and increased spike firing probability for each recording is summarized in Figure 12, $E$ and $F$, respectively. To determine more reliably whether LTP could influence spike generation, some cells were transiently depolarized $(5-20 \mathrm{mV})$ prior to and during synaptic stimulation; a fixed duration and amount of depolarization was used for a given cell during baseline and postoxytocin measurements.

It is likely that the initial increase in EPSP was due to reduced inhibition, allowing the synaptic inputs to more effectively depolarize the postsynaptic cell. The maintained enhancement of EPSP size, however, may be due to mechanisms of LTP or spiketiming-dependent plasticity (STDP) triggered by repetitive synaptic stimulation paired with reliable postsynaptic action potential generation (D'amour and Froemke, 2015). Because these mechanisms usually depend on activation of NMDA receptors (Froemke, 2015), we made recordings in ACSF containing the NMDA receptor antagonist APV $(50 \mu \mathrm{M})$ before oxytocin wash-in. APV fully blocked long-term changes in both EPSPs and spike generation (Fig. 12C,E,F) produced by oxytocin. Therefore, the long-term changes produced by a brief period of oxytocin wash-in required NMDA receptors, strongly suggesting that this enhancement of EPSP strength is a canonical form of LTP.

To determine whether disinhibition was sufficient to induce LTP and increase spike firing, we used the GABAA antagonist gabazine $(0.1 \mu \mathrm{M})$. Transient gabazine wash-in was effective at persistently enhancing EPSP slope and spike generation (Fig. $12 D-F)$ in a similar manner as oxytocin wash-in. These data support the hypothesis that a consequence of the disinhibitory action of oxytocin modulation is to enable LTP induction, likely by increasing synaptic strength from a subthreshold to a suprathreshold level and consequently inducing excitatory STDP (D'amour and Froemke, 2015).

These results from brain slices suggest that oxytocin modulation and plasticity may not simply be a special mechanism for enhancing responses to ultrasonic pup vocalizations. Instead, any sensory input might potentially be susceptible to oxytocin mod- 
A

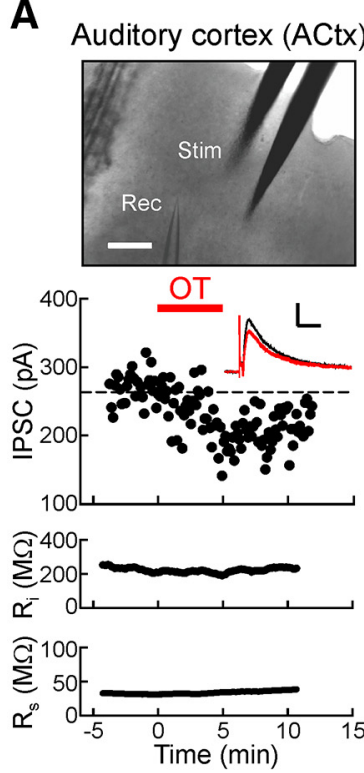

D

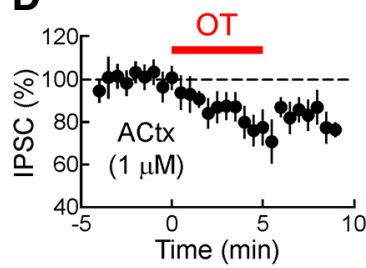

G

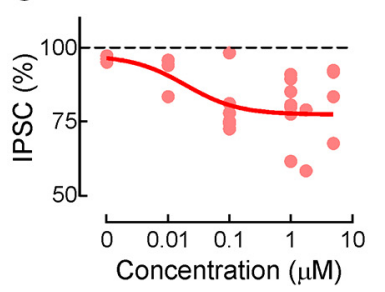

B

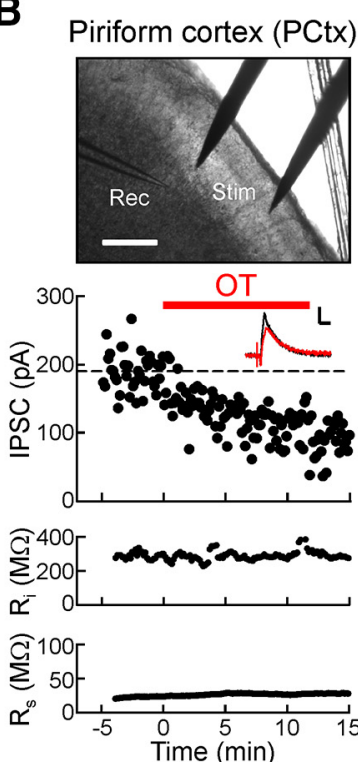

E

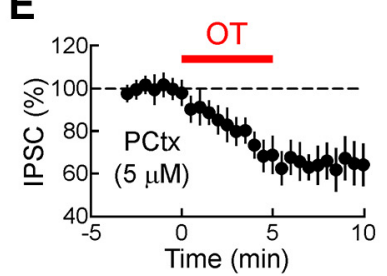

H

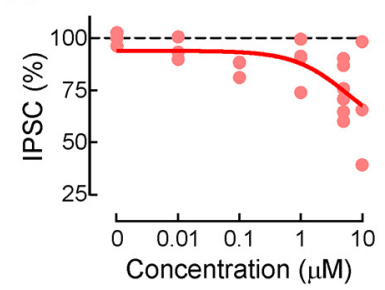

C

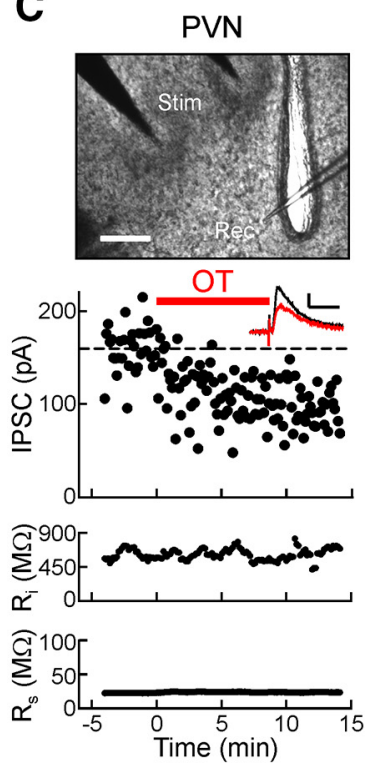

$F$

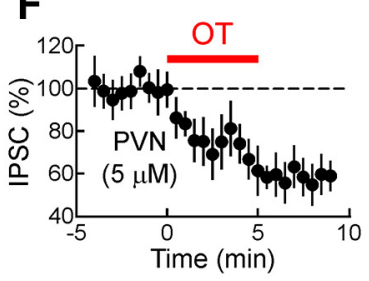

I

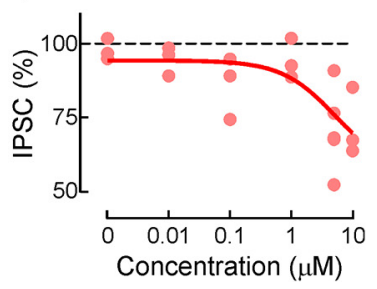

Figure 9. Exogenous oxytocin reduces synaptic inhibition. $\boldsymbol{A}$, Whole-cell voltage-clamp recording from layer 5 pyramidal neuron of mouse auditory cortex (ACtx) in vitro. Top, Photomicrograph of experimental setup. Scale bar, $200 \mu \mathrm{m}$. Middle, IPSCs evoked with extracellular stimulation. Oxytocin $(1 \mu \mathrm{m}$ ) washed into the bath decreased IPSC amplitude (baseline: $262.7 \pm 5.1 \mathrm{pA}$ 3-6 min after start of wash-in: $209.9 \pm 7.8 \mathrm{pA}$, reduced to $79.9 \%$ of baseline). Statistics are means \pm SEM. Inset, Average IPSC traces at baseline (black) and 3-6 min after wash-in (red). Scale bar, $5 \mathrm{~ms}, 20 \mathrm{pA}$. Bottom, $R_{\mathrm{i}}$ and $R_{\mathrm{s}}$ for this experiment, which each changed $<10 \%$ from baseline during wash-in. $\boldsymbol{B}$, Whole-cell voltage-clamp recording in piriform cortex (PCtx). Oxytocin (5 $\mu \mathrm{M})$ decreased IPSCS (baseline: $189.5 \pm 4.7$ pA, 3-6 min after wash-in: $129.9 \pm 4.1$ pA, reduced to $68.6 \%$ of baseline). Photomicrograph scale bar, $200 \mu \mathrm{m}$; inset scale bar, $5 \mathrm{~ms}, 25 \mathrm{pA}$. $R_{\mathrm{i}}$ changed $<5 \%$ and $R_{\mathrm{s}}$ changed $\sim 20 \%$ from baseline during wash-in. $C$, Whole-cell voltage-clamp recording in PVN. Oxytocin $(5 \mu \mathrm{m})$ decreased IPSCS (baseline: $159.0 \pm 4.6 \mathrm{pA}, 3-6$ min after wash-in: $110.4 \pm 6.1 \mathrm{pA}$, reduced to $69.4 \%$ of baseline). Photomicrograph scale bar, $200 \mu \mathrm{m}$; inset scale bar, $15 \mathrm{~ms}, 50 \mathrm{pA} . R_{\mathrm{i}}$ and $R_{\mathrm{s}}$ each changed $<10 \%$ from baseline during wash-in. $\boldsymbol{D}, 0 x y$ tocin $(1 \mu \mathrm{m})$ rapidly reduced IPSCs in auditory cortex within 3-6 min (decrease to $80.7 \pm 3.7 \%$ of baseline, $n=7, p<0.003$, Student's paired two-tailed $t$ test; decrease after $5-10$ min: $76.4 \pm 1.9 \%$ of baseline, $p<0.004)$. E, 0xytocin $(5 \mu \mathrm{m}$ ) reduced IPSCs in piriform cortex within $3-6 \mathrm{~min}$ (decrease to $74.7 \pm 4.5 \%$ of baseline, $n=6, p<0.004$; decrease after $5-10 \mathrm{~min}: 65.0 \pm 0.9 \%$ of baseline, $\left.p<10^{-6}\right)$. F, 0xytocin $(5 \mu \mathrm{M})$ reduced IPSC in PVN within $3-6 \min$ (decrease to $71.1 \pm 5.3 \%$ of baseline, $n=5, p<0.02$; decrease after $5-10 \mathrm{~min}: 58.5 \pm 1.1 \%$ of baseline, $p<10^{-5}$ ). $G$, Dose-response relationship for oxytocin and auditory cortex IPSCs. Oxytocin $(1-5 \mu \mathrm{m})$ reduced IPSCs by a comparable level $\left(p>0.7\right.$, ANOVA). Light red circles, Individual recordings; red line, sigmoidal fit (goodness-of-fit $\left.r^{2}=0.72, n=25\right)$. $\boldsymbol{H}$, Dose-response relationship for oxytocin and piriform cortex IPSCs (goodness-of-fit $\left.r^{2}=0.88, n=22\right)$. 0xytocin (5 and $10 \mu \mathrm{M}$ ) reduced IPSCs by a comparable level ( $p>0.7$, Student's unpaired two-tailed $t$ test). $I$, Dose-response relationship for oxytocin and PVN IPSCS (goodness-of-fit $\left.r^{2}=0.81, n=20\right)$. Oxytocin ( 5 and $\left.10 \mu \mathrm{M}\right)$ reduced IPSCs by a comparable level $(p>0.9$, Student's unpaired two-tailed $t$ test).

ulation. To test this hypothesis, we performed in vivo currentclamp recordings (Fig. 13A), single-unit cell-attached recordings (Fig. 13B), and multiunit extracellular recordings (Fig. 13C) from virgin female mouse primary auditory cortex (A1). For each re- cording type, we measured pure tone frequency tuning before and after pairing a specific tone with oxytocin for several minutes. We observed long-lasting changes to both synaptic and spiking responses of A1 neurons and multiunit ensembles to the paired tone for $10+$ minutes after pairing regardless of the frequency of the paired tone.

These data show conclusively that oxytocin disinhibits cortical neurons directly, boosting EPSP amplitude and converting subthreshold responses into suprathreshold spiking responses. This leads to mechanisms of NMDA-receptor-dependent plasticity that consolidate these enhancements and enable them to persist in absence of further oxytocin action. In this way, oxytocin might transiently increase the salience of incoming sensory input, enabling cortical circuits (and other oxytocin-sensitive brain regions) to form new memories of important social experiences.

\section{Discussion}

The distribution of oxytocin receptors in the mouse brain determines which components of neural circuits are directly sensitive to oxytocin modulation and thus form an important network for control of social behavior. Using a novel, specific antibody to the mouse oxytocin receptor OXTR-2, we found that oxytocin receptors were widely expressed throughout the CNS and detectable in many brain areas. Previous important studies using radiolabeled ligands and transgenic approaches have detected receptors in high abundance in certain brain regions, such as the PVN, lateral septum, nucleus accumbens, raphe nucleus, and amygdala (Elands et al., 1988; Insel and Shapiro, 1992; Yoshida et al., 2009). OXTR-2 immunoreactivity revealed differential receptor expression throughout the CNS. Importantly, no labeling with the antibody was detected in tissue sections from oxytocin receptor knock-out animals. We were also able to validate the specificity of our antibody using electron microscopy from wild-type and receptor knock-out mice.

The goal of our study was to determine the major features of the oxytocin circuitry in the mouse brain. We made four intriguing observations. First, we confirmed that oxytocin receptor expression was lateralized in the female mouse auditory cortex (Marlin et al., 2015) and delineated the "zone of lateralization" within the temporal lobe and over development. To ad- 
dress the lateralization of the receptor, we also examined mRNA levels using both qPCR and RNAseq and found that the levels of transcript followed similar patterns as oxytocin receptor protein expression, both in the left and right adult female auditory cortex, as well as in the overall developmental profile in auditory cortex and thalamus. The potential mechanisms for this surprising lateralization of both protein and transcript levels is unclear, but the oxytocin receptor is under tremendous control by various regulatory elements that provide potential for asymmetric expression (Gimpl and Fahrenholz, 2001). This has been best described in C. elegans, in which extensive regulatory networks control asymmetric left/right expression of receptor-type guanylyl cyclases in the ASE gustatory neurons and G-protein-coupled receptors in AWC olfactory neurons (Troemel et al., 1999; Hobert, 2014). Because activity in left auditory cortex is required for retrieval of isolated pups by maternal mice (Marlin et al., 2015), it is possible that there is a computational advantage in this form of clustered network organization for rapidly processing complex and ethologically important social stimuli such as infant distress calls for behavioral operation. One clue to the mechanisms underlying lateralized receptor expression might be the developmental time course of receptor expression. Lateralization was only apparent after the third postnatal week, which is particularly significant given that inhibitory responses begin to mature during this period in the rodent auditory cortex (Dorrn et al., 2010). It is possible that receptor lateralization might be part of a maturational program for specific types of cortical interneurons, including a subset of parvalbumin-positive and somatostatinpositive inhibitory cells that predominantly express oxytocin receptors (Nakajima et al., 2014; Marlin et al., 2015).

Second, CA2 and piriform cortex were especially enriched for oxytocin receptors in females. Together with left auditory cortex, these regions might form part of a distributed network for rodent maternal behaviors. There are several behaviors required for successful maternal care, which might be augmented or activated by oxytocin release (Sanchez-Andrade and Kendrick, 2009; Dulac et al., 2014; Rilling and Young, 2014). Beyond birthing and lactation, other maternal behaviors such as nest building, recognition of pup odor, or detection and rescue of isolated pups might rely on spatial, olfactory, and auditory memories enabled by oxytocin modulation and plasticity within CA2, piriform cortex, and left auditory cortex, as well as many other brain areas (Cui et al., 2013; Dulac et al., 2014; Rilling and Young, 2014; Grinevich et al., 2016). The abundance of oxytocin receptor expression in CA2 is particularly significant given the finding that this region of the hippocampus conveys signals to promote social interaction and memory (Hitti and Siegelbaum, 2014). Oxytocin receptor expression in mouse auditory cortex or PVN did not seem to be regulated by estrous. This may be a consequence of the rapid
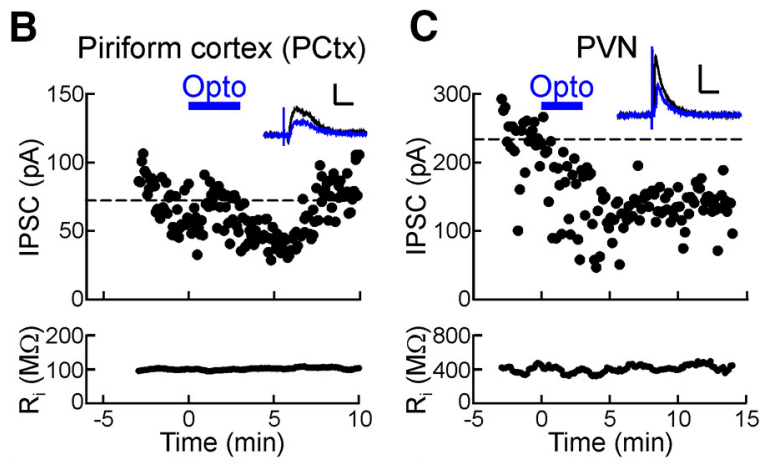

$E$

$\mathbf{F}$
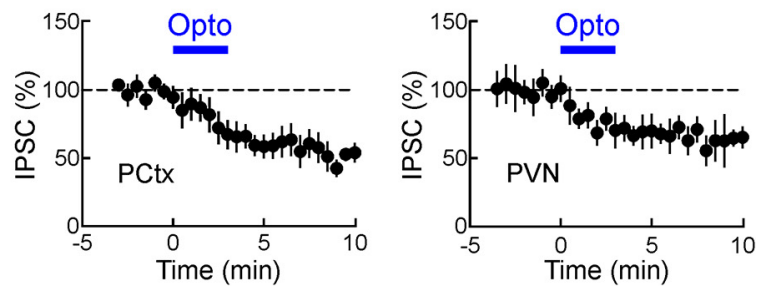

Figure 10. Endogenous oxytocin reduces synaptic inhibition. $\boldsymbol{A}$, Whole-cell voltage-clamp recording from layer 5 pyramidal (baseline: $115.0 \pm 4.0 \mathrm{pA}, 3-6$ min after start of optogenetic stimulation: $72.0 \pm 4.4 \mathrm{pA}$, reduced to $62.7 \%$ of baseline). Statistics (beM. Inset, Average IPSC traces at baseline (black) and 3-6 min after start of optogenetic stimulation (blue). Scale piriform cortex (decrease to $64.8 \pm 4.1 \%$ of baseline, $n=5, p<0.02$; decrease after $5-10 \mathrm{~min}: 60.9 \pm 4.2 \%$ of baseline, $p<$ 0.02 ). $\boldsymbol{F}$, Optogenetic stimulation reduced IPSC in PVN (decrease to $71.9 \pm 7.6 \%$ of baseline, $n=4, p<0.04$; decrease after $5-10$ $\min : 67.7 \pm 6.7 \%$ of baseline, $p<0.02$ ).

estrous cycling in mice and is comparable to findings examining radiolabeled oxytocin receptors in maternal rats (Insel, 1990) and rabbits (Jimenez et al., 2015).

Third, we found that oxytocin receptor activation modulates inhibitory transmission and controls long-term plasticity in vitro and in vivo, even for stimuli that are not a priori "social." We and others have found that oxytocin acts as a disinhibitory neuromodulator throughout the brain, rapidly decreasing evoked inhibitory events in the mouse piriform cortex and PVN, in the auditory cortex in vitro and in vivo (Marlin et al., 2015), and in hippocampal neurons in vitro (Owen et al., 2013). Disinhibition seems to be a general mechanism for modulating cortical circuits (Kruglikov and Rudy, 2008; Froemke, 2015). Consistent with this hypothesis, we previously found that oxytocin receptors were expressed primarily by cortical interneurons, specifically those that were parvalbumin-positive or somatostatin-positive (Marlin et al., 2015). This is similar to a recent study in transgenic mice in which somatostatin-positive inhibitory cells in mouse frontal cortex were found to express oxytocin receptors (Nakajima et al., 2014). At the electron microscopic level, it appeared that oxytocin receptors were located at excitatory and inhibitory synapses (both presynaptic and postsynaptic), along axons, and expressed by glial cells. Surprisingly, however, the predominant effect of oxytocin modulation is to reduce inhibitory transmission without directly affecting excitation. This was apparent after either pharmacological application of exogenous oxytocin or optogenetic release of endogenous oxytocin and was consistent across different brain areas: auditory cortex, piriform cortex, and 
A
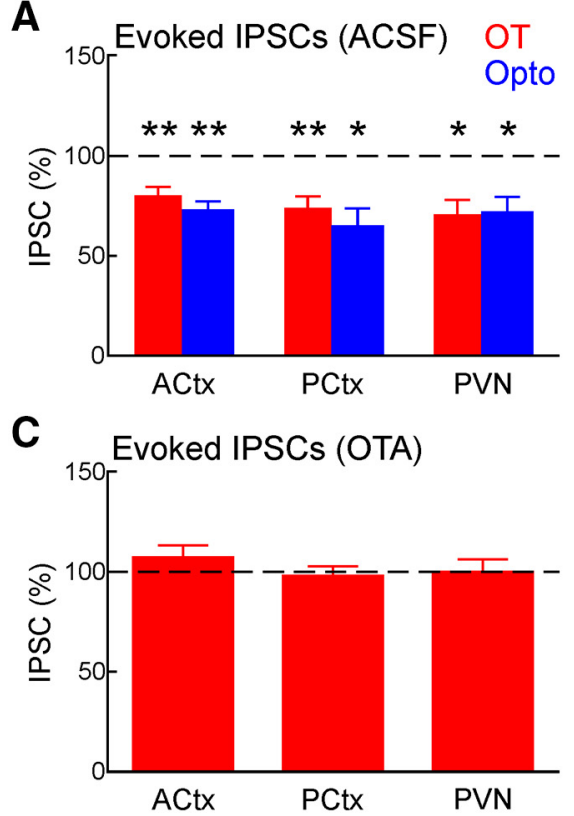

E

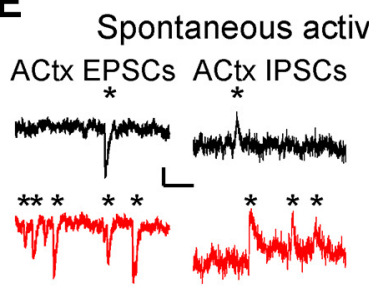

$\mathbf{F}$

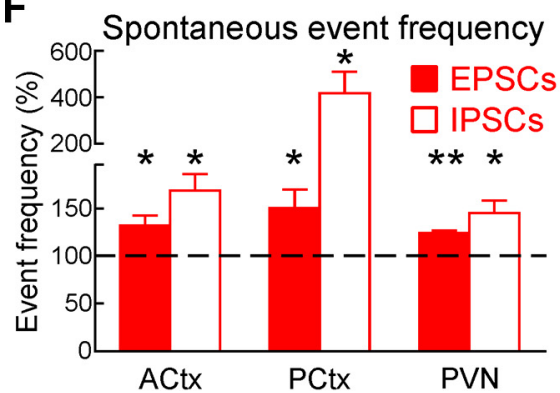

B

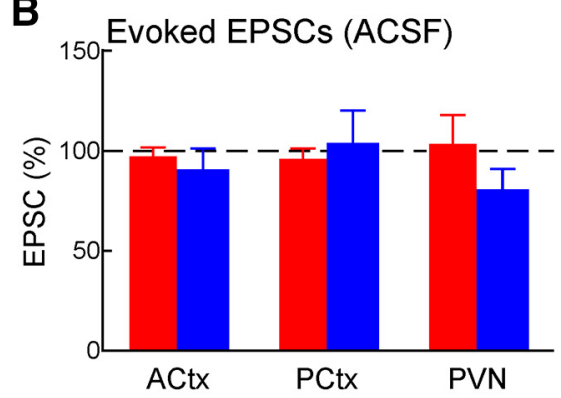

D Evoked IPSCs (DNQX/APV)

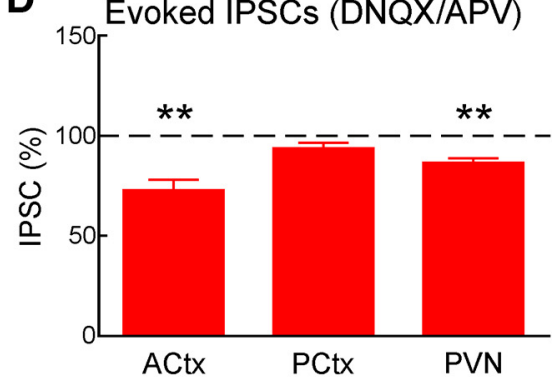

PVN in the present and previous study (Marlin et al., 2015) and also in the hippocampus (Owen et al., 2013). The disinhibitory effects of oxytocin may be triggered by oxytocin binding to receptors at synaptic terminals of inhibitory cells to reduce transmitter release or perhaps by activating somatic or axonal receptors to temporarily silence these neurons. In contrast to evoked IPSCs, however, spontaneous IPSCs were enhanced by oxytocin; this is consistent with previous findings in hippocampal slices from Owen et al. (2013), who suggested a mechanistic link among oxytocinergic depolarization of fast-spiking hippocampal interneurons, an increase in spontaneous firing of these neurons, subsequent increases in spontaneous inhibitory transmission, and then a reduction in available transmitter for evoked presynaptic spikes, ultimately decreasing evoked IPSC amplitude onto hippocampal pyramidal neurons. We hypothesize that a similar mechanism may occur in the cortex and PVN. Alternatively, the patterns of subcellular oxytocin receptor expression (on both presynaptic and postsynaptic sites) might indicate that control of spontaneous and evoked inhibition are independent and occur via distinct mechanisms.

G Spontaneous event amplitude

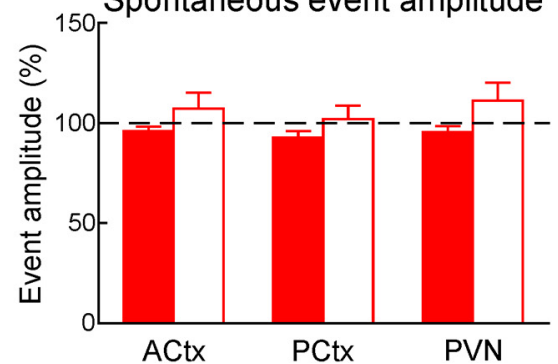

Figure 11. Oxytocin modulation of evoked and spontaneous activity in auditory cortex. $A, 0 x y$ tocin reduced evoked IPSCs within 3-6 $\min$ (auditory cortex $1 \mu \mathrm{m}$ oxytocin, decrease to $80.7 \pm 3.7 \%$ of baseline, $n=7, p<0.003$, Student's paired two-tailed $t$ test; auditory cortex optogenetics, decrease to $72.8 \pm 1.8 \%$ of baseline, $n=6, p<0.002$; piriform cortex $5 \mu \mathrm{m}$ oxytocin, decrease to $74.7 \pm 4.5 \%$ of baseline, $n=6, p<0.004$; piriform cortex optogenetics, decrease to $64.8 \pm 4.1 \%$ of baseline, $n=5, p<0.02$; PVN $5 \mu$ m oxytocin, decrease to $71.1 \pm 5.3 \%$ of baseline, $n=5, p<0.02$; PVN optogenetics, decrease to $71.9 \pm 7.6 \%$ of baseline, $n=4, p<0.04) .{ }^{*} p<0.05 ;{ }^{* *} p<0.01$. B, 0xytocin did not significantly affect evoked EPSCs in the first $3-6$ min (auditory cortex $1 \mu$ m oxytocin, $98.2 \pm 4.4 \%$ of baseline, $p>0.7$, Student's paired two-tailed $t$ test; auditory cortex optogenetics, $90.5 \pm 10.9 \%$ of baseline, $p>0.4$; piriform cortex $5 \mu$ m oxytocin, $97.0 \pm 4.4 \%$ of baseline, $p>0.5$; piriform cortex optogenetics, $103.5 \pm$ $16.8 \%$ of baseline, $p>0.8$; PVN $5 \mu$ m oxytocin, $104.5 \pm 13.6 \%$ of baseline, $p>0.7$; PVN optogenetics, $80.4 \pm 10.7 \%$ of baseline, $p>0.1)$. C, OTA $(1 \mu \mathrm{M})$ prevented oxytocinergic reduction of IPSCS (auditory cortex $1 \mu \mathrm{m}$ oxytocin, $107.4 \pm 5.9 \%$ of baseline, $n=$ $4, p>0.3$; piriform cortex $5 \mu$ m oxytocin, $98.1 \pm 4.8 \%$ of baseline, $n=4, p>0.7$; PVN $5 \mu$ m oxytocin, $100.1 \pm 6.3 \%$ of baseline, $n=3, p>0.9)$. D, Oxytocin reduced IPSCs in DNQX/APV ( 25 and $50 \mu \mathrm{M})$ in auditory cortex and PVN but not piriform cortex (auditory cortex $1 \mu \mathrm{m}$ oxytocin, decrease to $73.1 \pm 5.3 \%$ of baseline, $n=8, p<0.002$; piriform cortex $5 \mu \mathrm{m}$ oxytocin, $94.2 \pm$ $2.8 \%$ of baseline, $n=5, p>0.1$; PVN $5 \mu$ m oxytocin, decrease to $86.9 \pm 2.2 \%$ of baseline, $n=5, p<0.005$ ). E, Example periods of spontaneous activity before (black) and during oxytocin wash-in (red). Left, EPSCs and IPSCs from virgin female left auditory cortex. Scale bar, 100 ms, 10 pA. Middle, Piriform cortex. Scale bar, 25 ms, 10 pA. Right, PVN. Scale bar, 100 ms, 10 pA. *Detected events in each trace. $\boldsymbol{F}, 0 x y$ tocin increased spontaneous event frequency (auditory cortex $1 \mu \mathrm{m}$ oxytocin, spontaneous EPSC frequency increased to $133.1 \pm 10.3 \%$ of baseline, $p<0.04$; auditory cortex spontaneous IPSC frequency increased to $169.5 \pm$ $17.6 \%$ of baseline, $p<0.03$; piriform cortex $5 \mu$ m oxytocin, spontaneous EPSC frequency increased to $151.3 \pm 19.1 \%$ of baseline, $p<0.05$; piriform cortex spontaneous IPSC frequency increased to $422.1 \pm 92.0 \%$ of baseline, $p<0.04$; PVN $5 \mu \mathrm{m}$ oxytocin, spontaneous EPSC frequency increased to $124.8 \pm 2.8 \%$ of baseline, $p<0.004$; PVN spontaneous IPSC frequency increased to $145.9 \pm 13.3 \%$ of baseline, $p<0.05$ ). Filled bars, EPSCs; open bars, IPSCs. G, Oxytocin did not significantly affect spontaneous event amplitude (auditory cortex $1 \mu \mathrm{m}$ oxytocin, spontaneous EPSC amplitude was $96.4 \pm 2.3 \%$ of baseline, $p>0.1$; auditory
As a consequence of disinhibition, when we made recordings using currentclamp solution to measure EPSPs and spikes, we found that EPSPs were potentiated 10-20 min after oxytocin wash-in during and after increased spike firing evoked by extracellular stimulation. We hypothesize that this is a form of STDP in the auditory cortex enabled by disinhibition (D'amour and Froemke, 2015). In contrast, STDP of EPSCs was not observed, likely because EPSCs were monitored using voltageclamp solution in which spikes were blocked with QX-314. This dramatic increase in evoked spikes in the auditory cortex could serve as a potential mechanism for enabling animals to detect, recognize, or encode the behavioral significance of vocalizations or other sounds associated with a heightened oxytocinergic tone (which may reflect an important social context for such

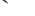

cortex spontaneous IPSC amplitude was $107.7 \pm 8.2 \%$ of baseline, $p>0.4$; piriform cortex $5 \mu$ m oxytocin, spontaneous form cortexspontaneous IPSC amplitude was $102.5 \pm 6.8 \%$ of baseline, $p>0.7$; PVN $5 \mu$ m oxytocin, spontaneous EPSC amplitude was $95.9 \pm 3.0 \%$ of baseline, $p>0.2$; PVN spontaneous IPSC amplitude was $111.8 \pm 8.9 \%$ of baseline, $p>0.2$ ). EPSC amplitude was $93.2 \pm 3.3 \%$ of baseline, $p>0.05$; piri- 

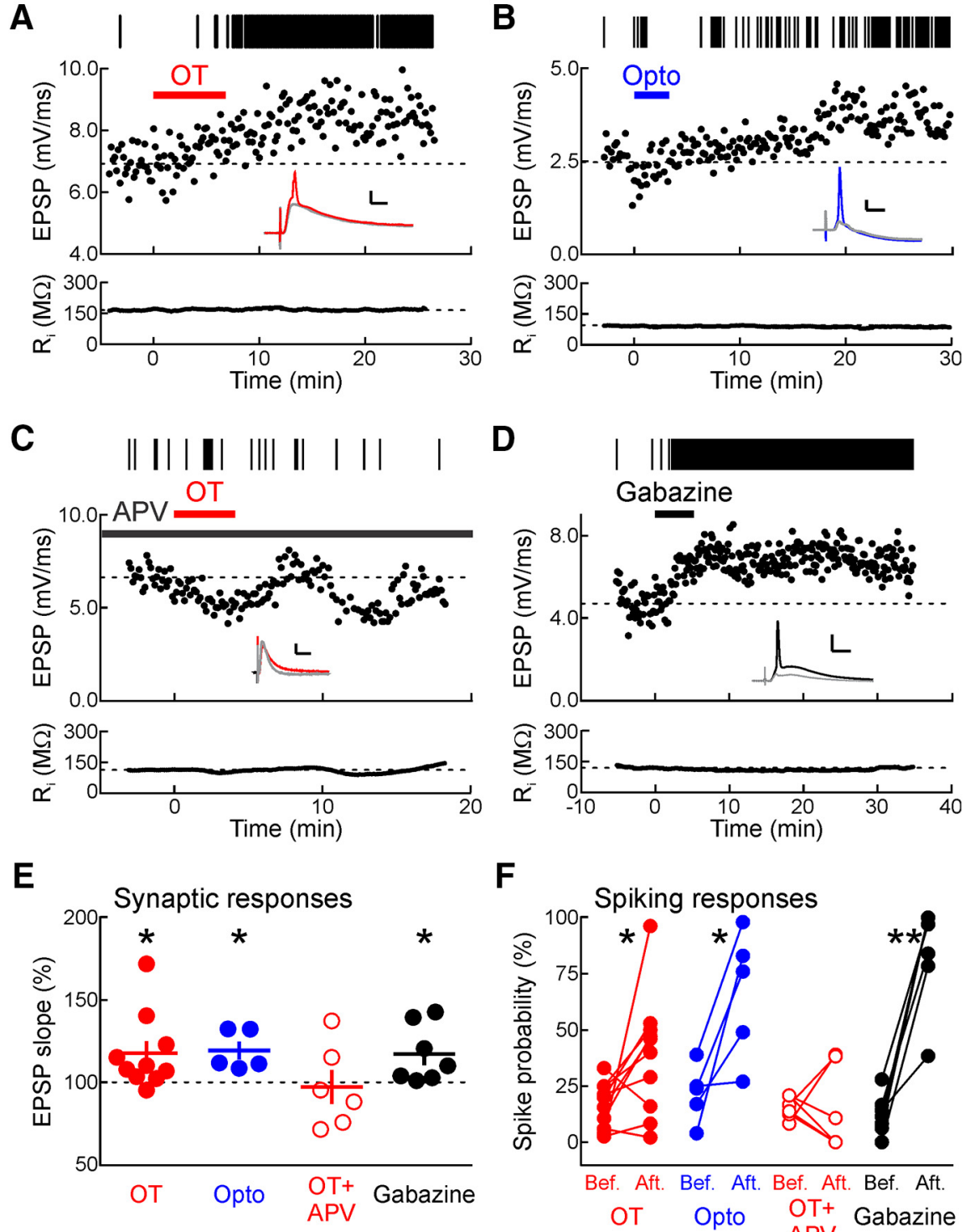

$\mathbf{F}$

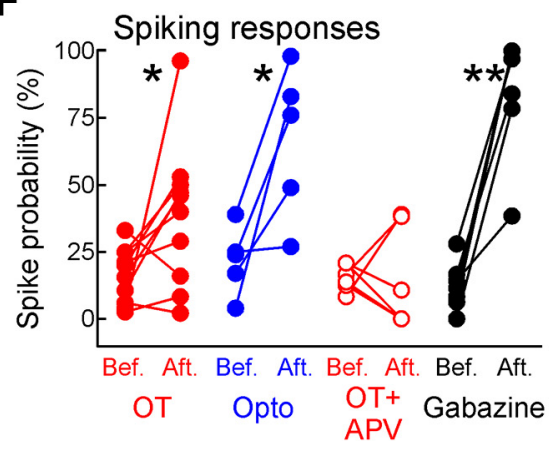

Figure 12. Oxytocin enables cortical plasticity in vitro. $\boldsymbol{A}$, Current-clamp recording from layer 5 pyramidal cell of virgin female auditory cortex in vitro. Oxytocin (0T, $5 \mu \mathrm{m}$, red bar) washed into the bath gradually increased EPSP slope (baseline: $6.9 \pm 0.1$ $\mathrm{mV} / \mathrm{msec}, 10-20 \mathrm{~min}$ after start of wash-in: $8.3 \pm 0.1 \mathrm{mV} / \mathrm{msec}$, increased to $120.6 \%$ of baseline) and spiking probability (upper raster plot, baseline: $4.0 \%$ of trials, $10-20$ min after wash-in: $96.3 \%$ of trials; cell was depolarized by $19 \mathrm{mV}$ ). Inset, Representative traces before (gray) and $\sim 15 \mathrm{~min}$ after (red) oxytocin wash-in. Scale bar, $10 \mathrm{~ms}, 10 \mathrm{mV} . R_{\mathrm{i}}$ of this neuron was stable (mean $R_{\mathrm{i}}$ before wash-in: $165.5 \mathrm{M} \Omega$, mean $R_{\mathrm{i}} 10-20$ min after wash-in: $166.8 \mathrm{M} \Omega$ ). $B$, Current-clamp recording from auditory cortex of virgin female Oxt-IRES-Cre animal. Optogenetic release of oxytocin (Opto, blue bar) increased EPSP slope (baseline: $2.5 \pm 0.1 \mathrm{mV} / \mathrm{msec}$, $10-20 \mathrm{~min}$ after start of optogenetic stimulation: $3.5 \pm 0.05 \mathrm{mV} / \mathrm{msec}$, increased to $141.6 \%$ of baseline) and spiking probability (upper raster plot, baseline: $18.2 \%$ of trials, $10-20$ min after start of optogenetic stimulation: $48.7 \%$ of trials; cell was depolarized by $19 \mathrm{mV}$ ). Inset, Representative traces before (gray) and $\sim 15$ min after (blue) optogenetic stimulation. Scale bar, $10 \mathrm{~ms}, 10 \mathrm{mV}$. $R_{\mathrm{i}}$ of this neuron was stable (mean $R_{\mathrm{i}}$ before: $92.4 \mathrm{M} \Omega$, mean $R_{\mathrm{i}} 10-20$ min after: $88.9 \mathrm{M} \Omega$ ). C, Current-clamp recording from layer 5 pyramidal cell of virgin female auditory cortex in vitro. Oxytocin wash-in ( $5 \mu \mathrm{m}$ oxytocin, red bar) in the presence of APV (50 $\mu \mathrm{m}$ APV, black bar) did not enhance EPSP slope (baseline: $6.6 \pm 0.1 \mathrm{mV} / \mathrm{msec}, 10-20 \mathrm{~min}$ after wash-in: $5.5 \pm 0.1 \mathrm{mV} / \mathrm{msec}$, decreased to $83.1 \%$ of baseline) or spiking probability (upper raster plot, baseline: $20.8 \%$ of trials, $10-20$ min after wash-in: $10.0 \%$ of trials; cell was depolarized by $12 \mathrm{mV}$ ). Inset, Representative traces before (gray) and $\sim 15$ min after oxytocin wash-in in APV (red). Scale bar, $20 \mathrm{~ms}, 5 \mathrm{mV} . R_{\mathrm{i}}$ of this neuron was stable (mean $R_{\mathrm{i}}$ before wash-in: $112.6 \mathrm{M} \Omega$, mean $R_{\mathrm{i}} 10-20$ min after wash-in: $112.1 \mathrm{M} \Omega)$. $\boldsymbol{D}$, Current-clamp recording from layer 5 pyramidal cell of virgin female auditory cortex in vitro. Gabazine $(0.1 \mu \mathrm{m}$, black bar) washed into the bath gradually increased EPSP slope (baseline: $4.8 \pm 0.1 \mathrm{mV} / \mathrm{msec}, 10-20 \mathrm{~min}$ after start of wash-in: $6.8 \pm 0.1 \mathrm{mV} / \mathrm{msec}$, increased to $145.5 \%$ of baseline) and spiking probability (upper raster plot, baseline: $6.3 \%$ of trials, $10-20$ min after wash-in: $100.0 \%$ of trials; cell was depolarized by $12 \mathrm{mV}$ ). Inset, Representative traces before (gray) and $\sim 15 \mathrm{~min}$ after gabazine wash-in (black). Scale bar, $10 \mathrm{~ms}, 25 \mathrm{mV}$. Bottom, $R_{\mathrm{i}}$ of this neuron was stable (mean $R_{\mathrm{i}}$ before wash-in: $122.1 \mathrm{M} \Omega$, mean $\mathrm{R}_{\mathrm{i}} 10-20$ min after wash-in: $108.9 \mathrm{M} \Omega$ ). E, 0 xytocin or gabazine enabled long-term plasticity of synaptic responses in vitro. Mean change in EPSP slope after oxytocin wash-in (5 $\mu \mathrm{m}$, mean increase to $117.7 \pm 7.2 \%$ of baseline, $n=10, p<0.04$; Student's paired two-tailed $t$ test), optogenetic release of oxytocin (mean increase to $119.3 \pm 5.4 \%$ of baseline, $n=5, p<0.03$ ), oxytocin in APV (5 $\mu \mathrm{M}$ oxytocin, $50 \mu \mathrm{M}$ APV, $97.2 \pm 10.2 \%$ of baseline, $n=6, p>0.7)$, or gabazine wash-in $(0.1 \mu \mathrm{m}$, mean increase to sounds). In this manner, disinhibition due to oxytocin modulation may increase the salience of incoming auditory information, allowing animals to rapidly learn the meaning of pup calls (Marlin et al., 2015) or other arbitrarily complex sounds emitted by infants or adults.

Although inhibitory events were consistently reduced in each of the three brain regions examined here (auditory cortex, piriform cortex, and PVN), there may be important distinctions in the mechanisms and details of oxytocinergic modulation in different circuits. Although IPSCs were reduced by oxytocin in auditory cortex and PVN when excitatory receptors were blocked, DNQX/APV prevented disinhibition in the piriform cortex. This suggests that inhibitory events onto piriform cortex cells were triggered disynaptically by stimulation of excitatory inputs into interneurons. It is also possible that optogenetic stimulation of oxytocinergic fibers leads to corelease of other neurotransmitters or neuromodulators that regulate inhibition, such as glutamate (Kendrick et al., 1988; Richard et al., 1991). Furthermore, oxytocin greatly increased the rate of spontaneous inhibition onto excitatory piriform neurons, providing an alternative mechanism for oxytocinergic disinhibition. In the auditory cortex and PVN, we hypothesize that oxytocin receptors on presynaptic inhibitory terminals might directly decrease GABA release, whereas in the piriform cortex, oxytocin receptor activation might hyperpolarize excitatory cells, preventing them from driving inhibitory cells. Inhibitory events in piriform cortex and PVN were also modulated at higher concentrations of oxytocin than in the

$117.2 \pm 6.6 \%$ of baseline, $n=7, p<0.05) .{ }^{*} p<0.05 . \boldsymbol{F}$, 0xytocin or gabazine enabled long-term enhancement of spike firing in auditory cortex. Mean trial-by-trial spiking probabilities before and $10-20 \mathrm{~min}$ after oxytocin wash-in (Bef., spike probability per trial before oxytocin: $16.3 \pm 3.2 \%$; Aft., spiking probability after oxytocin: $38.8 \pm 8.6 \%, n=10, p<$ 0.05 ) before and $10-20 \mathrm{~min}$ after optogenetic release of oxytocin (spike probability per trial before optogenetic stimulation: $21.8 \pm 5.7 \%$, spiking probability after optogenetic stimulation: $66.6 \pm 12.7 \%, n=5, p<0.03)$, before and $10-20$ min after oxytocin in APV (spiking probability before oxytocin in APV: $15.5 \pm 2.0 \%$, spiking probability after oxytocin in APV: $14.7 \pm 7.8 \%, n=6, p>0.9)$, or before and $10-20$ min after gabazine wash-in (spike probability per trial before gabazine: $12.2 \pm 3.4 \%$, spiking probability after gabazine: $85.4 \pm 8.5 \%, n=7, p<0.0002$ ). Same recordings as in E. ${ }^{*} p<0.05 ;{ }^{* *} p<0.01$. Statistics and error bars are means \pm SEM. 
A

\section{Synaptic frequency tuning}

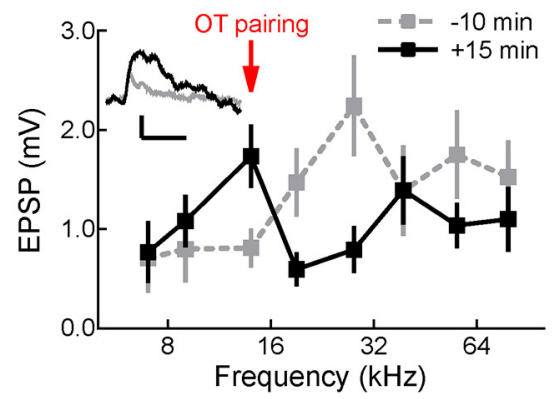

B

Spiking frequency tuning (single-unit)

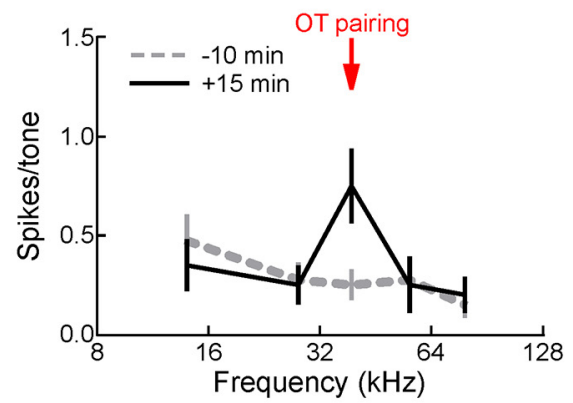

C

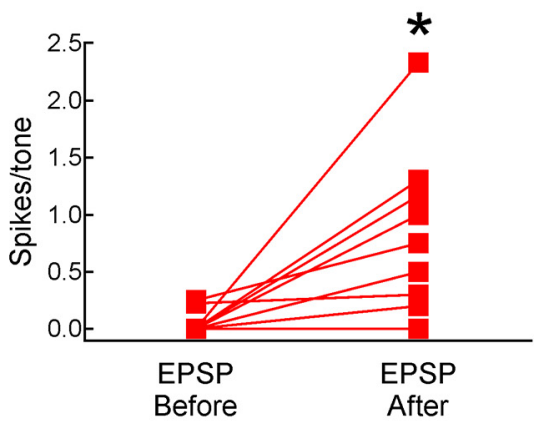

Spiking frequency tuning (multi-unit)
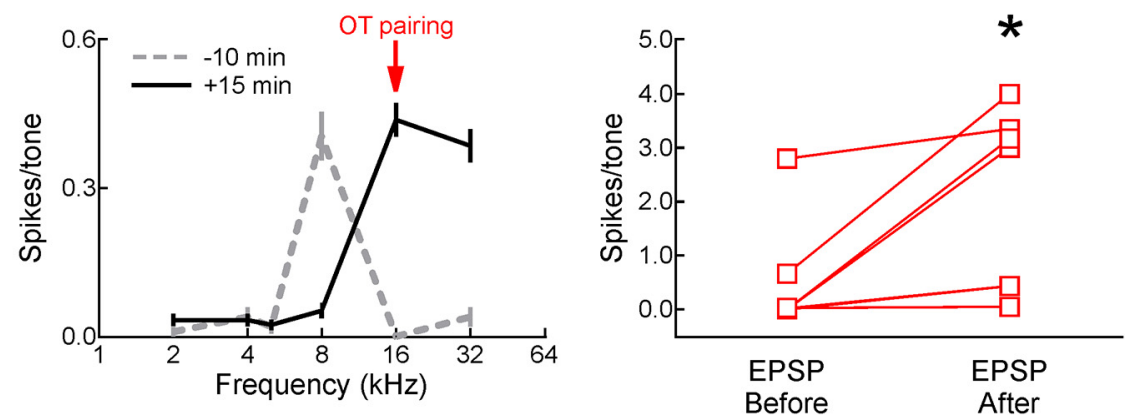

Figure 13. Oxytocin enables cortical plasticity in vivo. $\boldsymbol{A}$, Whole-cell current-clamp recordings in virgin female mice of synaptic responses to pure tones before and after oxytocin pairing. Left, Averaged tone-evoked responses from an example whole-cell recording of Al frequency tuning in vivo. After measuring baseline frequency tuning, topical application of oxytocin was paired with $14 \mathrm{kHz}$ tones (arrow) and tuning curves measured 11-20 min afterward (gray dashed line, baseline responses to $14 \mathrm{kHz}$ tones: $0.8 \pm 0.2 \mathrm{mV}$; black solid line, 11-20 min after pairing: $1.7 \pm 0.3 \mathrm{mV}$; increase of $214.4 \%$ from baseline, $p<0.03$, Student's unpaired two-tailed $t$ test). Inset, Example EPSPs evoked by paired $14 \mathrm{kHz}$ tones before (gray) and 11-20 min after (black) pairing. Scale bar, $1 \mathrm{mV}, 50 \mathrm{~ms}$. Right, Summary of EPSPs measured in current-clamp mode. Tone-evoked synaptic responses at the paired frequency were increased after pairing (mean increase 11-20 min after pairing to $167.7 \pm 20.0 \%$ of baseline, $n=4$ neurons, $p<$ 0.05 , Student's paired two-tailed $t$ test). $B$, Single-unit (cell-attached) recordings of spiking in virgin female left auditory cortex before and after oxytocin pairing. Left, Average tone-evoked responses from cell-attached recording of frequency tuning before and 11-20 min after oxytocin pairing with $39 \mathrm{kHz}$ tones (gray dashed line, baseline responses to $39 \mathrm{kHz}$ tones: $0.25 \pm 0.08$ spikes/tone, $11-20$ min after pairing: $0.75 \pm 0.19$ spikes/tone, $p<0.03$, Student's unpaired two-tailed $t$ test). Right, Summary of single-unit recordings before and after pairing (before pairing: $0.05 \pm 0.03$ spikes/tone, $11-20 \mathrm{~min}$ after pairing: $0.76 \pm 0.23$ spikes/tone, $n=10$ neurons, $p<0.02$, Student's paired two-tailed $t$ test). $C$, Extracellular recordings of multiunit activity in vivo before and after oxytocin pairing. Left, Average tone-evoked responses from multiunit recording before and 11-20 min after pairing oxytocin with $16 \mathrm{kHz}$ tones (gray dashed line, baseline responses to $16 \mathrm{kHz}$ tones: $0.0 \pm 0.0$ spikes/tone; black solid line, 11-20 min after pairing: $0.44 \pm 0.03$ spikes/tone; $p<10^{-4}$, Student's unpaired two-tailed $t$ test). Right, Summary of multiunit recordings before and after pairing (before pairing: $0.50 \pm 0.39$ spikes/tone, $11-20 \mathrm{~min}$ after pairing: $2.06 \pm 0.63$ spikes/tone, $n=7$ recordings, $p<0.04$, Student's paired two-tailed $t$ test).

auditory cortex. This higher concentration requirement may be due to differences in effectors downstream of G-proteinsignaling mechanisms that link oxytocin receptor activation to changes in transmitter release, such as those described by
Owen et al. (2013) in hippocampal slices. Alternatively, the greater sensitivity to oxytocin of auditory cortical inhibitory events may be a consequence of a lower baseline amount of oxytocin release and/or receptor desensitization in auditory cortex compared with piriform cortex and PVN.

Consistent with previous studies in transgenic mice, glial cells were previously shown to express oxytocin receptors in OXTR-Venus knock-in animals (Yoshida et al., 2009). Glial expression of oxytocin receptors is interesting because it may allow these cells to sense ambient oxytocin peptide levels in CSF or blood, enabling these cells to appropriately regulate release of oxytocin and other neurohormones (Panatier, 2009; Yoshida et al., 2009). Moreover, oxytocin might directly stimulate hormone release from astrocytes (Parent et al., 2008). Further studies are required to understand how glial oxytocin receptors may be important regulators of social behaviors and neuroendocrine signaling.

Finally, we observed oxytocinreleasing axons in many diverse regions in transgenic animals expressing YFP only in these cells. There was little relation between axonal distributions and oxytocin receptor expression profiles, as observed for some other transmitter systems (Herkenham, 1987). This suggests that the specificity of target structures for oxytocin modulation is a purview of the postsynaptic excitatory and inhibitory neurons in these regions. Our study may have been underpowered to see more fine-grain differences in oxytocin receptors or oxytocinergic axon branches within individual circuits. However, this indicates that oxytocin release may act broadly as a classic volume-transmitted neuromodulator across the CNS. Consonant with these hypotheses, the dose-response relations that we examined indicate that inhibitory transmission is less sensitive to low concentrations of oxytocin in brain regions that express oxytocin receptors more densely; this includes the PVN, which highly expressed oxytocin receptors and had many YFP+ oxytocinergic axons. There appeared to be extensive oxytocin-positive axon fibers projecting within and between the PVN and SON. This observation is especially interesting given our electrophysiological recordings from PVN neurons showing that the PVN is rapidly disinhibited by oxytocin. This modulation of inhibitory tone might help to coordinate excitability and firing patterns across these two regions, ensuring a substantial and homogeneous pattern of oxytocin release throughout the 
brain for multimodal control of information processing. It remains to be determined precisely what types of sensory stimuli and behavioral episodes (social or otherwise) activate these neurons for central oxytocin release.

\section{References}

Anders S, Pyl PT, Huber W (2015) HTSeq-a Python framework to work with high-throughput sequencing data. Bioinformatics 31:166-169. CrossRef Medline

Barkat TR, Polley DB, Hensch TK (2011) A critical period for auditory thalamocortical connectivity. Nat Neurosci 14:1189-1194. CrossRef Medline

Bartz JA, Zaki J, Bolger N, Ochsner KN (2011) Social effects of oxytocin in humans: context and person matter. Trends Cogn Sci 15:301-309. Medline

Biddle FG, Eales BA (1996) The degree of lateralization of paw usage (handedness) in the mouse is defined by three major phenotypes. Behav Genet 26:391-406. CrossRef Medline

Byers SL, Wiles MV, Dunn SL, Taft RA (2012) Mouse estrous cycle identification tool and images. PLoS One 7:e35538. CrossRef Medline

Caligioni CS (2009) Assessing reproductive status/stages in mice. Curr Protoc Neurosci Appendix 4:Appendix 4I. CrossRef Medline

Cohen Y, Putrino D, Wilson DA (2015) Dynamic cortical lateralization during olfactory discrimination learning. J Physiol 593:1701-1714. CrossRef Medline

Cui Z, Gerfen CR, Young WS 3rd (2013) Hypothalamic and other connections with dorsal CA2 area of the mouse hippocampus. J Comp Neurol 521:1844-1866. CrossRef Medline

D'amour JA, Froemke RC (2015) Inhibitory and excitatory spike-timingdependent plasticity in the auditory cortex. Neuron 86:514-528. CrossRef Medline

Dölen G, Darvishzadeh A, Huang KW, Malenka RC (2013) Social reward requires coordinated activity of nucleus accumbens oxytocin and serotonin. Nature 501:179-184. CrossRef Medline

Dorrn AL, Yuan K, Barker AJ, Schreiner CE, Froemke RC (2010) Developmental sensory experience balances cortical excitation and inhibition. Nature 465:932-936. CrossRef Medline

Dulac C, O'Connell LA, Wu Z (2014) Neural control of maternal and paternal behaviors. Science 345:765-770. CrossRef Medline

Ehret G (1987) Left hemisphere advantage in the mouse brain for recognizing ultrasonic communication calls. Nature 325:249-251. CrossRef Medline

Elands J, Beetsma A, Barberis C, de Kloet ER (1988) Topography of the oxytocin receptor system in rat brain: an autoradiographical study with a selective radioiodinated oxytocin antagonist. J Chem Neuroanat 1:293302. Medline

Franklin KBJ, Paxinos G (2007) The mouse brain in stereotaxic coordinates, Ed 3.

Froemke RC (2015) Plasticity of cortical excitatory-inhibitory balance. Annu Rev Neurosci 38:195-219. CrossRef Medline

Froemke RC, Jones BJ (2011) Development of auditory cortical synaptic receptive fields. Neurosci Biobehav Rev 35:2105-2113. CrossRef Medline

Gimpl G, Fahrenholz F (2001) The oxytocin receptor system: structure, function, and regulation. Physiol Rev 81:629-683. Medline

Grinevich V, Knobloch-Bollmann HS, Eliava M, Busnelli M, Chini B (2016) Assembling the puzzle: pathways of oxytocin signaling in the brain. Biol Psychiatry 79:155-164. Medline

Guo Y, Ye F, Sheng Q, Clark T, Samuels DC (2014a) Three-stage quality control strategies for DNA re-sequencing data. Brief Bioinform 15:879889. CrossRef Medline

Guo Y, Zhao S, Sheng Q, Ye F, Li J, Lehmann B, Pietenpol J, Samuels DC, Shyr Y (2014b) Multi-perspective quality control of Illumina exome sequencing data using QC3. Genomics 103:323-328. CrossRef Medline

Guo Y, Zhao S, Ye F, Sheng Q, Shyr Y (2014c) MultiRankSeq: multiperspective approach for RNAseq differential expression analysis and quality control. Biomed Res Int 2014:248090. Medline

Gutkowska J, Jankowski M, Lambert C, Mukaddam-Daher S, Zingg HH, McCann SM (1997) Oxytocin releases atrial natriuretic peptide by combining with oxytocin receptors in the heart. Proc Natl Acad Sci U S A 94:11704-11709. CrossRef Medline

Haberly LB, Bower JM (1989) Olfactory cortex: model circuit for study of associative memory? Trends Neurosci 12:258-264. CrossRef Medline
Hackett TA, Clause AR, Takahata T, Hackett NJ, Polley DB (2015) Differential maturation of vesicular glutamate and GABA transporter expression in the mouse auditory forebrain during the first weeks of hearing. Brain Struct Funct. In press.

Harris JA, Hirokawa KE, Sorensen SA, Gu H, Mills M, Ng LL, Bohn P, Mortrud M, Ouellette B, Kidney J, Smith KA, Dang C, Sunkin S, Bernard A, Oh SW, Madisen L, Zeng H (2014) Anatomical characterization of Cre driver mice for neural circuit mapping and manipulation. Front Neural Circuits 8:76. Medline

Herkenham M (1987) Mismatches between neurotransmitter and receptor localizations in brain: observations and implications. Neuroscience 23:138. CrossRef Medline

Hitti FL, Siegelbaum SA (2014) The hippocampal CA2 region is essential for social memory. Nature 508:88-92. CrossRef Medline

Hobert O (2014) Development of left/right asymmetry in the Caenorhabditis elegans nervous system: from zygote to postmitotic neuron. Genesis 52:528-543. CrossRef Medline

Insel TR (1990) Regional changes in brain oxytocin receptors post-partum: time-course and relationship to maternal behaviour. J Neuroendocrinol 2:539-545. CrossRef Medline

Insel TR, Shapiro LE (1992) Oxytocin receptor distribution reflects social organization in monogamous and polygamous voles. Proc Natl Acad Sci U S A 89:5981-5985. CrossRef Medline

Insel TR, Young LJ (2001) The neurobiology of attachment. Nat Rev Neurosci 2:129-136. CrossRef Medline

Irani BG, Donato J Jr, Olson DP, Lowell BB, Sacktor TC, Reyland ME, Tolson KP, Zinn AR, Ueta Y, Sakata I, Zigman JM, Elias CF, Clegg DJ (2010) Distribution and neurochemical characterization of protein kinase C-theta and -delta in the rodent hypothalamus. Neuroscience 170:10651079. CrossRef Medline

Jiménez A, Young LJ, Río RT, LaPrairie JL, González-Mariscal G (2015) Neuroanatomical distribution of oxytocin receptor binding in the female rabbit forebrain: variations across the reproductive cycle. Brain Res 1629: 329-339. CrossRef Medline

Kendrick KM, Keverne EB, Chapman C, Baldwin BA (1988) Microdialysis measurement of oxytocin, aspartate, gamma-aminobutyric acid and glutamate release from the olfactory bulb of the sheep during vaginocervical stimulation. Brain Res 442:171-174. CrossRef Medline

Kim D, Pertea G, Trapnell C, Pimentel H, Kelley R, Salzberg SL (2013) TopHat2: accurate alignment of transcriptomes in the presence of insertions, deletions and gene fusions. Genome Biol 14:R36. CrossRef Medline

Kimura T, Tanizawa O, Mori K, Brownstein MJ, Okayama H (1992) Structure and expression of a human oxytocin receptor. Nature 356:526-529. CrossRef Medline

Knobloch HS, Charlet A, Hoffmann LC, Eliava M, Khrulev S, Cetin AH, Osten P, Schwarz MK, Seeburg PH, Stoop R, Grinevich V (2012) Evoked axonal oxytocin release in the central amygdala attenuates fear response. Neuron 73:553-566. CrossRef Medline

Koch M, Ehret G (1989) Estradiol and parental experience, but not prolactin are necessary for ultrasound recognition and pup-retrieving in the mouse. Physiol Behav 45:771-776. CrossRef Medline

Kruglikov I, Rudy B (2008) Perisomatic GABA release and thalamocortical integration onto neocortical excitatory cells are regulated by neuromodulators. Neuron 58:911-924. CrossRef Medline

Kubota Y, Kimura T, Hashimoto K, Tokugawa Y, Nobunaga K, Azuma C, Saji F, Murata Y (1996) Structure and expression of the mouse oxytocin receptor gene. Mol Cell Endocrinol 124:25-32. CrossRef Medline

Livak KJ, Schmittgen TD (2001) Analysis of relative gene expression data using real-time quantitative PCR and the $2^{-\Delta \Delta C}$ method. Methods 25: 402-408. CrossRef Medline

Marlin BJ, Mitre M, D'amour JA, Chao MV, Froemke RC (2015) Oxytocin enables maternal behavior by balancing cortical inhibition. Nature 520: 499-504. CrossRef Medline

McCarthy MM (1990) Oxytocin inhibits infanticide in female house mice (Mus domesticus). Horm Behav 24:365-375. CrossRef Medline

Nagai T, Ibata K, Park ES, Kubota M, Mikoshiba K, Miyawaki A (2002) A variant of yellow fluorescent protein with fast and efficient maturation for cell-biological applications. Nat Biotechnol 20:87-90. CrossRef Medline

Nakajima M, Görlich A, Heintz N (2014) Oxytocin modulates female sociosexual behavior through a specific class of prefrontal cortical interneurons. Cell 159:295-305. CrossRef Medline

Nedelescu H, Kelso CM, Lázaro-Muñoz G, Purpura M, Cain CK, Ledoux JE, 
Aoki C (2010) Endogenous GluR1-containing AMPA receptors translocate to asymmetric synapses in the lateral amygdala during the early phase of fear memory formation: an electron microscopic immunocytochemical study. J Comp Neurol 518:4723-4739. CrossRef Medline

Nishimori K, Young LJ, Guo Q, Wang Z, Insel TR, Matzuk MM (1996) Oxytocin is required for nursing but is not essential for parturition or reproductive behavior. Proc Natl Acad Sci U S A 93:11699-11704. CrossRef Medline

Olazábal DE, Young LJ (2006) Oxytocin receptors in the nucleus accumbens facilitate "spontaneous" maternal behavior in adult female prairie voles. Neuroscience 141:559-568. CrossRef Medline

Owen SF, Tuncdemir SN, Bader PL, Tirko NN, Fishell G, Tsien RW (2013) Oxytocin enhances hippocampal spike transmission by modulating fastspiking interneurons. Nature 500:458-462. CrossRef Medline

Pagani JH, Zhao M, Cui Z, Avram SK, Caruana DA, Dudek SM, Young WS (2015) Role of the vasopressin $1 \mathrm{~b}$ receptor in rodent aggressive behavior and synaptic plasticity in hippocampal area CA2. Mol Psychiatry 20:490499. CrossRef Medline

Panatier A (2009) Glial cells: indispensable partners of hypothalamic magnocellular neurones. J Neuroendocrinol 21:665-672. CrossRef Medline

Parent AS, Rasier G, Matagne V, Lomniczi A, Lebrethon MC, Gérard A, Ojeda SR, Bourguignon JP (2008) Oxytocin facilitates female sexual maturation through a glia-to-neuron signaling pathway. Endocrinology 149: 1358-1365. CrossRef Medline

Pedersen CA, Prange AJ Jr (1979) Induction of maternal behavior in virgin rats after intracerebroventricular administration of oxytocin. Proc Natl Acad Sci U S A 76:6661-6665. CrossRef Medline

Peters A, Palay SL, Webster HF (1991) The fine structure of the nervous system: neurons and their supporting cells. Oxford: OUP.

Postina R, Kojro E, Fahrenholz F (1996) Separate agonist and peptide antagonist binding sites of the oxytocin receptor defined by their transfer into the V2 vasopressin receptor. J Biol Chem 271:31593-31601. CrossRef Medline

Richard P, Moos F, Freund-Mercier MJ (1991) Central effects of oxytocin. Physiol Rev 71:331-370. Medline

Richter K, Wolf G, Engelmann M (2005) Social recognition memory requires two stages of protein synthesis in mice. Learn Mem 12:407-413. CrossRef Medline

Rilling JK, Young LJ (2014) The biology of mammalian parenting and its effects on offspring social development. Science 345:771-776. CrossRef Medline

Sanchez-Andrade G, Kendrick KM (2009) The main olfactory system and social learning in mammals. Behav Brain Res 200:323-335. CrossRef Medline

Staff NP, Spruston N (2003) Intracellular correlate of EPSP-spike potentiation in CA1 pyramidal neurons is controlled by GABAergic modulation. Hippocampus 13:801-805. CrossRef Medline

Sweatt DJ (2009) Long-term potentiation- a candidate cellular mechanism for information storage in the central nervous system. In: Mechanisms of memory (Sweatt DJ, ed), Ed 2. San Diego: Academic.

Takayanagi Y, Yoshida M, Bielsky IF, Ross HE, Kawamata M, Onaka T, Yanagisawa T, Kimura T, Matzuk MM, Young LJ, Nishimori K (2005) Pervasive social deficits, but normal parturition, in oxytocin receptordeficient mice. Proc Natl Acad Sci U S A 102:16096-16101. CrossRef Medline

Tribollet E, Charpak S, Schmidt A, Dubois-DauphinM, Dreifuss JJ (1989) Appearance and transient expression of oxytocin receptors in fetal, infant, and peripubertal rat brain studied by autoradiography and electrophysiology. J Neurosci 9:1764-1773. Medline

Troemel ER, Sagasti A, Bargmann CI (1999) Lateral signaling mediated by axon contact and calcium entry regulates asymmetric odorant receptor expression in C. elegans. Cell 99:387-398. CrossRef Medline

Tyzio R, Cossart R, Khalilov I, Minlebaev M, Hübner CA, Represa A, Ben-Ari Y, Khazipov R (2006) Maternal oxytocin triggers a transient inhibitory switch in GABA signaling in the fetal brain during delivery. Science 314: 1788-1792. CrossRef Medline

Tyzio R, Nardou R, Ferrari DC, Tsintsadze T, Shahrokhi A, Eftekhari S, Khalilov I, Tsintsadze V, Brouchoud C, Chazal G, Lemonnier E, Lozovaya N, Burnashev N, Ben-Ari Y (2014) Oxytocin-mediated GABA inhibition during delivery attenuates autism pathogenesis in rodent offspring. Science 343:675-679. CrossRef Medline

Wacker DW, Ludwig M (2012) Vasopressin, oxytocin, and social odor recognition. Horm Behav 61:259-265. CrossRef Medline

Waters EM, Thompson LI, Patel P, Gonzales AD, Ye HZ, Filardo EJ, Clegg DJ, Gorecka J, Akama KT, McEwen BS, Milner TA (2015) G-proteincoupled estrogen receptor 1 is anatomically positioned to modulate synaptic plasticity in the mouse hippocampus. J Neurosci 35:2384-2397. CrossRef Medline

Wu Z, Xu Y, Zhu Y, Sutton AK, Zhao R, Lowell BB, Olson DP, Tong Q (2012) An obligate role of oxytocin neurons in diet induced energy expenditure. PLoS One 7:e45167. CrossRef Medline

Yoshida M, Takayanagi Y, Inoue K, Kimura T, Young LJ, Onaka T, Nishimori K (2009) Evidence that oxytocin exerts anxiolytic effects via oxytocin receptor expressed in serotonergic neurons in mice. J Neurosci 29:2259 2271. CrossRef Medline 